\title{
Parallel shape divergence between ecotypes of the limpet Nacella concinna along the Antarctic Peninsula: a new model species for parallel evolution?
}

\author{
María Carla de Aranzamendi ${ }^{\text {a,b,*, Juan José Martínez }}{ }^{c}$, Christoph Held ${ }^{\text {d }}$, Ricardo Sahade ${ }^{\text {a,b, } *}$ \\ ${ }^{a}$ Universidad Nacional de Córdoba, Facultad de Ciencias Exactas, Físicas y Naturales, Cátedra de Ecología Marina, Av. Vélez Sarsfield 299, X5000JJC, Córdoba, \\ Argentina

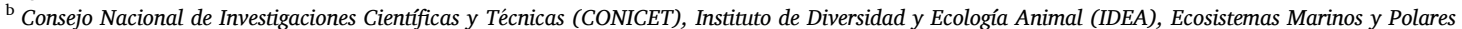 \\ (ECOMARES), Av. Vélez Sarsfield 299, X5000JJC, Córdoba, Argentina \\ ${ }^{\mathrm{c}}$ Laboratorio de Ecología Evolutiva y Biogeografía, Instituto de Ecorregiones Andinas (INECOA), CONICET and Universidad Nacional de Jujuy, C. Gorriti 237, San \\ Salvador de Jujuy, 4600, Argentina \\ ${ }^{\mathrm{d}}$ Alfred-Wegener-Institut Helmholtz-Zentrum für Polar- und Meeresforschung, Am Handelshafen 12, D-27570 Bremerhaven, Germany
}

\section{A R T I C L E I N F O}

\section{Keywords:}

Cytochrome Oxidase subunit I

eco-evolutionary dynamics

outline analysis

phenotypic trajectories

shell morphology

phenotypic plasticity

\begin{abstract}
A B S T R A C T
Parallel phenotypic divergence is the independent differentiation between phenotypes of the same lineage or species occupying ecologically similar environments in different populations. We tested in the Antarctic limpet Nacella concinna the extent of parallel morphological divergence in littoral and sublittoral ecotypes throughout its distribution range. These ecotypes differ in morphological, behavioural and physiological characteristics. We studied the lateral and dorsal outlines of shells and the genetic variation of the mitochondrial gene Cytochrome Oxidase subunit I from both ecotypes in 17 sample sites along more than $2,000 \mathrm{~km}$. The genetic data indicate that both ecotypes belong to a single evolutionary lineage. The magnitude and direction of phenotypic variation differ between ecotypes across sample sites; completely parallel ecotype-pairs (i.e., they diverge in the same magnitude and in the same direction) were detected in $84.85 \%$ of lateral and $65.15 \%$ in dorsal view comparisons. Besides, specific traits (relative shell height, position of shell apex, and elliptical/pear-shape outline variation) showed high parallelism. We observed weak morphological covariation between the two shape shell views, indicating that distinct evolutionary forces and environmental pressures could be acting on this limpet shell shape. Our results demonstrate there is a strong parallel morphological divergence pattern in $N$. concinna along its distribution, making this Antarctic species a suitable model for the study of different evolutionary forces shaping the shell evolution of this limpet.
\end{abstract}

\section{Introduction}

Parallel phenotypic divergence is the differentiation between particular phenotypes of the same lineage or species, which is repeated similarly in different populations with alike environmental gradients (Endler, 1986; Schluter et al., 2004). It could be strong evidence for the role of natural selection (Endler, 1986; Schluter et al., 2004; Roda et al., 2013; Agrawal, 2017). However, it has been argued that parallel phenotypic divergence could be also enhanced or reduced by plasticity (Oke et al., 2016). In consequence, the natural replication of phenotypic divergence across populations provides the opportunity for studying underlying processes of phenotypic evolution and for understanding the roles of natural selection, genetic drift, gene flow and plasticity on the origin of parallel phenotypic divergence (e.g., Westram et al., 2014; Ravinet et al., 2016; Hamilton et al., 2020; Jacobs et al., 2020; Westram et al., 2021).

When studying the existence of parallel divergence, it is useful to know that replicate ecotypes or populations vary in the magnitude or even in the direction of trait evolution (Stuart et al., 2017). Studies on different ecotypes of fishes (e.g., lake versus stream, benthic vs. limnetic, high predation vs. low predation, sulfidic vs. non-sulfidic) highlight the importance of quantifying parallelism rather than just affirming its presence (Oke et al., 2017; Jacobs et al., 2020). Indeed, the detection of low extents of parallelism provides relevant opportunities to investigate

\footnotetext{
* Corresponding authors at: Consejo Nacional de Investigaciones Científicas y Técnicas (CONICET), Instituto de Diversidad y Ecología Animal (IDEA); Universidad Nacional de Córdoba, Facultad de Ciencias Exactas, Físicas y Naturales, Argentina.

E-mail addresses: mcdearanzamendi@conicet.gov.ar (M.C. de Aranzamendi), jjmartinez@conicet.gov.ar (J.J. Martínez), christoph.held@awi.de (C. Held), rsahade@unc.edu.ar (R. Sahade).
} 
the factors that shape phenotypic divergence (Oke et al., 2017). Important insights can be yielded by taking a multitrait perspective such as overall morphology, or ecological niche, and quantifying parallelism as replicated evolutionary trajectories or as the amount of variation explained by parallel phenotypic divergence (Butlin et al., 2014; Stuart et al., 2017; Langerhans, 2018; Martinez et al., 2018; Jacobs et al., 2020).

Here, we assess the phenotypic trajectories of parallel divergence between ecotypes of the Antarctic limpet Nacella concinna (Strebel, 1908) (Gastropoda: Patellogastropoda). This widely distributed and abundant macroinvertebrate is one of the few species inhabiting the littoral zone of the Antarctic Peninsula (AP) and islands along the Scotia Arc (González-Wevar et al., 2013). This limpet lives from the littoral down to around $100 \mathrm{~m}$ depth in the sublittoral zone (Powell, 1951; Walker, 1972), where environmental factors and acting stressors are very different (Peck et al., 2006; Marcías et al., 2017). In the littoral zone, limpets are exposed to desiccation, wave action, ice crushing and avian predation, while the sublittoral area provides a more stable or protected environment (Shabica, 1976; Nolan, 1991; Weihe and Abele, 2008; Morley et al., 2010; Castillo et al., 2019). Two ecotypes have been described in this limpet associated with different environments and shell morphology (Walker, 1972). In fact, some studies on this Antarctic species detected phenotypic differences between ecotypes in morphological, physiological, and behavioural traits (Nolan, 1991; Markowska and Kidawa, 2007; Weihe and Abele, 2008; de Aranzamendi et al., 2010; Hawes et al., 2010; Clark et al., 2018; Lomovasky et al., 2020). The Sublittoral ecotype has flatter and triangular shells and dwells in the sublittoral zone throughout the year (between $\sim 4$ - $110 \mathrm{~m}$ depth; see Fig. 1). The Littoral ecotype is taller, thicker and heavier with a globose shape shell; it is present in the littoral for most of the year and migrates to the sublittoral zone at the beginning of autumn (Nolan, 1991; Weihe and Abele, 2008; de Aranzamendi et al., 2010; Castillo et al., 2019; Lomovasky et al., 2020). This vertical and seasonal migration might occur as a response to air temperature changes and ice formation in the littoral. Therefore, both ecotypes coexist in the sublittoral zone during winter, whilst in summer they are spatially separated with an overlapping zone between them in the shallow sublittoral (Walker, 1972). The migration behaviour has been questioned since at Ryder Bay Littoral individuals have also been found to remain in the littoral during winter, which means that, at least in this location, not all individuals migrate to the sublittoral (Waller et al., 2006; Obermüller et al., 2011).

Population genetic studies using different molecular markers were conducted to analyse the contemporary gene flow between the two ecotypes in this species, but with disparate results (Beaumont and Wei, 1991; de Aranzamendi et al., 2008; Hoffman et al., 2010; Chwedorzewska et al., 2010). Utilizing inter simple sequence repeat (ISSR) markers, de Aranzamendi et al. (2008) detected low but significant genetic structure between ecotypes. In contrast, no genetic differences were found using allozyme loci (Beaumont and Wei, 1991). By using AFLPs, Hoffman et al. (2010) did not detect genetic structure between ecotypes, attributing the morphological separation to phenotypic plasticity. However, Chwedorzewska et al. (2010) also with AFLPs found low but significant genetic differences but attributed the morphological divergence to phenotypic plasticity expressed in particular environmental conditions, rather than to genetic differentiation. Taking the two ecotypes as a single panmictic population, genetic differentiation was found mostly among geographically distant populations of $N$. concinna with different demographic history and levels of genetic diversity (Hoffman et al., 2011; González-Wevar et al., 2013). However, a fine-scale genetic structure between very close populations of this limpet was detected in Adelaide Island (Hoffman et al., 2012).

Ascertaining the extent to which ecotype divergence is repeatable is essential for predicting biodiversity and phenotypic responses to environmental change. The Southern Ocean has experienced significant changes in temperature and seasonal ice dynamics for more than 30 years, with severe impacts on the regional ecosystem, ocean chemistry and hydrographic properties (Constable et al., 2014). Considering that the magnitude and direction of these changes differ between areas, populations of the same species might be affected differently (Henley et al., 2019; Rogers et al., 2020). Therefore, this work aims to help understanding the evolutionary routes leading to replicated ecological divergence by conducting a biogeographic study that examines the shell morphology variation and extent of morphological parallelism of the two ecotypes in the Antarctic limpet $N$. concinna along the coast of the AP. We studied the lateral and dorsal outlines of shells by means of Elliptic Fourier analysis (EFA), multivariate linear models and trajectory analysis from Littoral and Sublittoral ecotypes. The molecular variation of a mitochondrial gene Cytochrome Oxidase subunit I (COI) fragment was assessed to determine the presence of distinct evolutionary lineages.

\section{Materials and methods}

\subsection{Sample collection}

A total of 485 individuals of $N$. concinna were sampled at 11 stations along the Antarctic Peninsula during the "Antarctic Mission" of the sailship Sedna IV (2006), during the Antarctic Summer Campaigns in Carlini Station (2006, 2009; Potter Cove, Isla 25 de Mayo/King George Island, South Shetlands Islands) and tissue samples for molecular analysis were obtained from South Georgia Islands (Table 1, Fig. 2). In two stations, Potter Cove and Ryder Bay, four substations were sampled. In the majority of the stations and substations (hereafter referred to as "sample sites"), limpets were collected at two different depths: littoral (L) and sublittoral (SL), to sample the two ecotypes present in this species. By ecotype we refer to a group of individuals with adaptive phenotypic differences linked to a marked ecological gradient (Lowry, 2012). In one sample site of Potter Cove, Peñón Cero, an extra sample at SL $4 \mathrm{~m}$ was included only in the analyses and visualisations of shape variation to analyse the possible admixture of both ecotypes at an intermediate depth. The $\mathrm{L}$ samples were collected by hand at $0 \mathrm{~m}$ water depth, while SL ones by scuba divers at different depths (see Table 1). In five sample sites, only L samples are available because it was not possible to dive (Esperanza Bay, South Georgia Island, Pinitos, Peñón de Pesca and New Island; the last three are sample sites at Potter Cove station). All sample
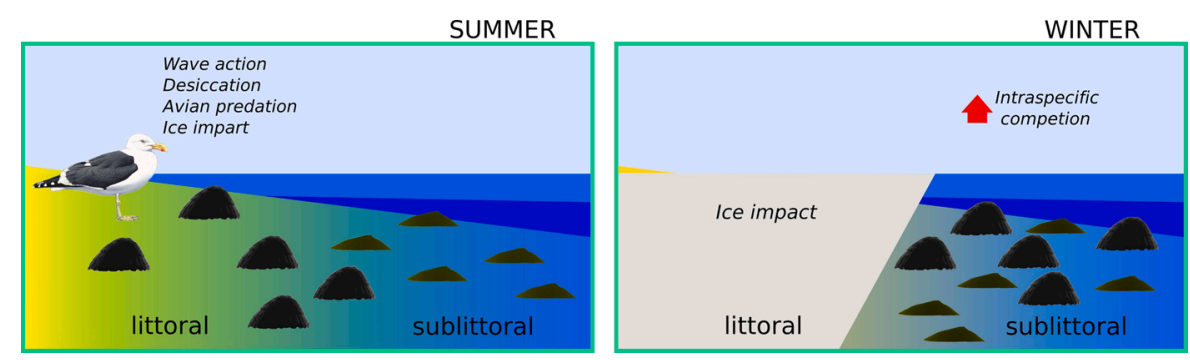

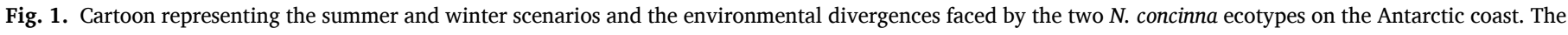
arrow indicates increased intraspecific competition in the shallow sublittoral. 
Table 1

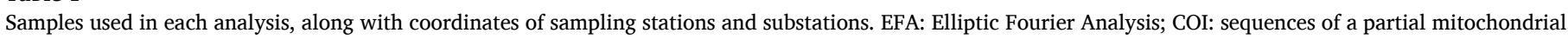

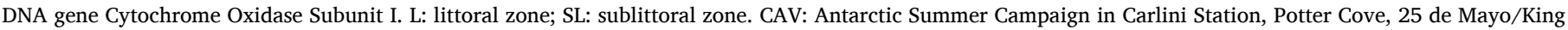

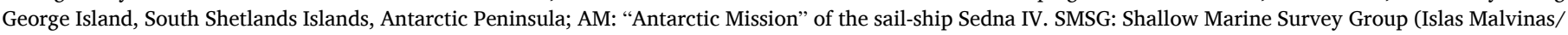
Falkland Islands). n: number of samples.

\begin{tabular}{|c|c|c|c|c|c|c|}
\hline Sample site & abbreviations & Depth & n (EFA) & $\mathrm{n}(\mathrm{COI})$ & Coordinates & Campaign \\
\hline \multirow{3}{*}{ Peñón Cero-Potter Cove } & \multirow{3}{*}{ PC-P0 } & $\mathrm{L}$ & 13 & 5 & \multirow{3}{*}{$62^{\circ} 14^{\prime} 51.4^{\prime \prime} \mathrm{S}, 58^{\circ} 40^{\prime} 58.8^{\prime \prime} \mathrm{W}$} & \multirow{3}{*}{ CAV 2006} \\
\hline & & SL $4 \mathrm{~m}$ & 14 & - & & \\
\hline & & SL $15 \mathrm{~m}$ & 26 & 8 & & \\
\hline Peñón de Pesca-Potter Cove & PC-PP & $\mathrm{L}$ & 19 & 3 & $62^{\circ} 14^{\prime} 3.8^{\prime \prime} \mathrm{S}, 58^{\circ} 42^{\prime} 42.5^{\prime \prime} \mathrm{W}$ & CAV 2009 \\
\hline Pinitos-Potter Cove & PC-P & $\mathrm{L}$ & - & 3 & $62^{\circ} 14^{\prime} 18.7^{\prime \prime} \mathrm{S}, 58^{\circ} 42^{\prime} 42.5^{\prime \prime} \mathrm{W}$ & CAV 2006 \\
\hline New Island-Potter Cove & PC-NI & $\mathrm{L}$ & 16 & 4 & $62^{\circ} 13^{\prime} 27.84^{\prime \prime} \mathrm{S}, 58^{\circ} 39^{\prime} 57.89^{\prime \prime} \mathrm{W}$ & CAV 2009 \\
\hline Esperanza Bay & $\mathrm{EB}$ & $\mathrm{L}$ & 15 & 10 & $63^{\circ} 24^{\prime} \mathrm{S} ; 56^{\circ} 59^{\prime} \mathrm{W}$ & AM 2006 \\
\hline \multirow{2}{*}{ Melchior Island } & \multirow{2}{*}{ ME } & $\mathrm{L}$ & 20 & 6 & \multirow{2}{*}{$64^{\circ} 24^{\prime} 40.78^{\prime \prime} \mathrm{S}, 62^{\circ} 52^{\prime} 34.99^{\prime \prime} \mathrm{W}$} & \multirow{2}{*}{ AM 2006} \\
\hline & & SL $20 \mathrm{~m}$ & 17 & 1 & & \\
\hline \multirow{2}{*}{ Charlotte Bay } & \multirow{2}{*}{$\mathrm{CB}$} & $\mathrm{L}$ & 20 & - & \multirow{2}{*}{$64^{\circ} 34^{\prime} 59^{\prime \prime} \mathrm{S}, 61^{\circ} 37^{\prime} 59^{\prime \prime} \mathrm{W}$} & \multirow{2}{*}{ AM 2006} \\
\hline & & SL $30 \mathrm{~m}$ & 22 & 1 & & \\
\hline \multirow{2}{*}{ Anvers Island } & \multirow{2}{*}{ AI } & $\mathrm{L}$ & 28 & 8 & \multirow{2}{*}{$64^{\circ} 46^{\prime} 30^{\prime \prime} \mathrm{S}, 64^{\circ} 04^{\prime} \mathrm{W}$} & \multirow{2}{*}{ AM 2006} \\
\hline & & SL $20 \mathrm{~m}$ & 26 & 8 & & \\
\hline \multirow{2}{*}{ Paradise Bay } & \multirow{2}{*}{ PB } & $\mathrm{L}$ & 15 & 5 & \multirow{2}{*}{$64^{\circ} 53^{\prime} \mathrm{S}, 62^{\circ} 53^{\prime} \mathrm{W}$} & \multirow{2}{*}{ AM 2006} \\
\hline & & SL $15 \mathrm{~m}$ & 16 & 3 & & \\
\hline \multirow{2}{*}{ Renaud Island } & \multirow{2}{*}{ RI } & $\mathrm{L}$ & 11 & 8 & \multirow{2}{*}{$65^{\circ} 52^{\prime} 56.5^{\prime \prime}$ S, $66^{\circ} 05^{\prime} 37.2^{\prime \prime} \mathrm{W}$} & \multirow{2}{*}{ AM 2006} \\
\hline & & SL $20 \mathrm{~m}$ & 18 & 3 & & \\
\hline \multirow{2}{*}{ Fish Island } & \multirow{2}{*}{ FI } & $\mathrm{L}$ & 19 & 1 & \multirow{2}{*}{$66^{\circ} 2^{\prime} \mathrm{S}, 65^{\circ} 25^{\prime} \mathrm{W}$} & \multirow{2}{*}{ AM 2006} \\
\hline & & SL $10 \mathrm{~m}$ & 15 & 2 & & \\
\hline \multirow{2}{*}{ East Beach-Ryder Bay } & \multirow{2}{*}{ RB-EB } & $\mathrm{L}$ & 11 & 6 & $67^{\circ} 34^{\prime}{ }^{\prime} 9^{\prime \prime} \mathrm{s} 68^{\circ} 07^{\prime} 048^{\prime}, \mathrm{W}$ & \\
\hline & & SL $20 \mathrm{~m}$ & 21 & 5 & $67^{\circ} 34^{\prime} 19^{\prime \prime} \mathrm{S}, 68^{\circ} 07^{\prime} 04.8^{\prime \prime} \mathrm{W}$ & AM 2006 \\
\hline & & $\mathrm{L}$ & 18 & - & 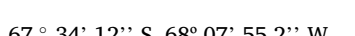 & АМ 2006 \\
\hline South Cove-Ryder Bay & RB-SC & SL $20 \mathrm{~m}$ & 16 & - & $67^{\circ} 34^{\prime} 12^{\prime \prime} \mathrm{S}, 68^{\circ} 07^{\prime} 55.2^{\prime \prime} \mathrm{W}$ & AM 2006 \\
\hline North Cove-Ryder Bay & RB-NC & $\mathrm{L}$ & 16 & - & $67^{\circ} 34^{\prime} 032^{\prime \prime} \mathrm{S} 68^{\circ} 06^{\prime} 519^{\prime \prime} \mathrm{W}$ & AM 2006 \\
\hline North Cove-kyder Bay & RB-NC & SL $20 \mathrm{~m}$ & 13 & - & $67 \quad 3403.2 \mathrm{~s}, 6806 \quad 51.9^{\circ} \mathrm{W}$ & \\
\hline Tiny Cove-Ryder Bay & RB-TC & $\mathrm{L}$ & 12 & - & $67^{\circ} 34^{\prime} 05^{\prime \prime}$ s. $68^{\circ} 09^{\prime} 003^{\prime \prime}, \mathrm{W}$ & AM 2006 \\
\hline & & SL $20 \mathrm{~m}$ & 8 & - & & \\
\hline Mikkelsen Island & & $\mathrm{L}$ & 16 & 3 & $67^{\circ} 38^{\prime} \mathrm{s} 68^{\circ} 1^{\prime} \mathrm{w}$ & M 2006 \\
\hline Mikkelsen Island & MI & SL $15 \mathrm{~m}$ & 17 & 2 & $67^{\circ} 38^{\prime} \mathrm{S}, 68^{\circ} 11^{\prime} \mathrm{W}$ & AM 2006 \\
\hline South Georgia Islands & SG & $\mathrm{L}$ & - & 18 & $54^{\circ} 10^{\prime} 17^{\prime \prime} \mathrm{S}, 36^{\circ} 40^{\prime} 24.6^{\prime \prime} \mathrm{W}$ & SMSG 2010 \\
\hline & & & $\mathrm{n}_{\mathrm{T}}=464$ & $=113$ & & \\
\hline
\end{tabular}

sites were collected in summer (between January and February) when the two ecotypes are spatially separated (see Fig. 1). For the phenotypic analyses, we used only adult individuals (i.e., with a shell length greater than $20 \mathrm{~mm}$; see Walker, 1972). Samples were labelled and preserved in $96 \%$ ethanol. The final dataset comprises 17 sample sites (12 with $\mathrm{L}$ and SL ecotype-pairs, totalling 30 sample units), whereas different subsets were used for the genetic and morphometric analyses (Table 1).

\subsection{Genetic analyses}

To estimate evolutionary lineages between ecotypes along the AP, we chose to work with a fragment of the mitochondrial COI gene since with other markers already used in this species (such as AFLP and ISSR), the phylogenetic component is often highly compromised (Zink and Barrowclough, 2008). Therefore, we sequenced 113 individuals belonging to different sample sites and depths (Table 1). Total DNA was extracted from foot tissue using standard protocols for the DNeasy Blood and Tissues Kit (QIAGEN, Düsseldorf, Germany). A partial fragment (623 bp) of the mitochondrial DNA (mtDNA) gene Cytochrome Oxidase Subunit I (COI) was amplified using primers LCO1490 (5'-GGT-CAA-CAA-ATC-ATA-AAG-ATA-TTG-G-3'; Folmer et al., 1994) and COI-NacR (5'-AAT-AAA-TGC-TGA-TAA-AGA-ATA-3'; González-Wevar et al., 2011a). Amplification was performed in a $25 \mu \mathrm{l}$ reaction volume, containing approximately $15 \mathrm{ng}$ of total DNA, $0.5 \mu \mathrm{M}$ of each primer, $0.2 \mathrm{mM}$ dNTPs, 1x PCR buffer and $0.05 \mathrm{U}$ of 5-Prime Hotmaster Taq DNA Polymerase. Initial denaturation for $3 \mathrm{~min}$ at $94^{\circ} \mathrm{C}$ was followed by 36 cycles of $94^{\circ} \mathrm{C}$ for $60 \mathrm{~s}, 50{ }^{\circ} \mathrm{C}$ for $60 \mathrm{~s}, 72{ }^{\circ} \mathrm{C}$ for $90 \mathrm{~s}$ and a final extension at $72{ }^{\circ} \mathrm{C}$ for $7 \mathrm{~min}$. PCR products were sequenced (forward and reverse strands) by Macrogen Inc. (Seoul, Korea) and the Alfred-Wegener-Institute (AWI; Bremerhaven, Germany).

Sequences were assembled using CHROMAS v. 2.6.2 (Technelysium Pty Ltd, Tewantin Qld, Australia) and manually edited if necessary.
Additionally, we included 28 sequences that correspond to 28 haplotypes of $N$. concinna reported in González-Wevar et al. (2013) and available in GenBank to cover all possible known genetic and geographic variability in the species (GenBank accession numbers: KF261314-KF261341). The sequences were aligned using MAFFT v. 7 (Katoh et al., 2019), trimmed to a common length and collapsed into haplotypes with DnaSP v. 6 (Rozas et al., 2017; alignment matrix available at https://doi.org/10.6084/m9.figshare.13053194.v1). The number of polymorphic sites was calculated using DnaSP. Two median-joining networks were constructed with POPART v. 1.7 (Leigh and Bryant, 2015) to estimate the relationships among haplotypes. The first network shows the relationships among haplotypes taking into account the sample sites using all sequenced samples in this study and the sequences from GenBank. The second one classifies the samples by depth and includes only our samples from AP and adjoined islands (95 sequences). The overall mean genetic distance and pairwise genetic distances between haplotypes were calculated using p-distances in Mega v. 7 (Kumar et al., 2016). All new $N$. concinna haplotypes sequences were uploaded to GenBank (accession numbers: MT796036-MT796042).

\subsection{Morphometric analyses}

The morphological dataset does not include samples from Pinitos (PC-P) and South Georgia Islands (SG) since no shells were available from these sites (Table 1). All shells analysed are stored in the scientific collection of the Instituto de Diversidad y Ecología Animal (IDEA, CONICET-UNC).

The shell shape of these limpets is rather simple and was quantified by means of EFA already by previous studies (de Aranzamendi et al., 2010; Castillo et al., 2019). Therefore, EFA on the outline coordinates was used in this work to assess the shape differences of the individuals (Rohlf and Archie, 1984; for more details, see de Aranzamendi et al., 


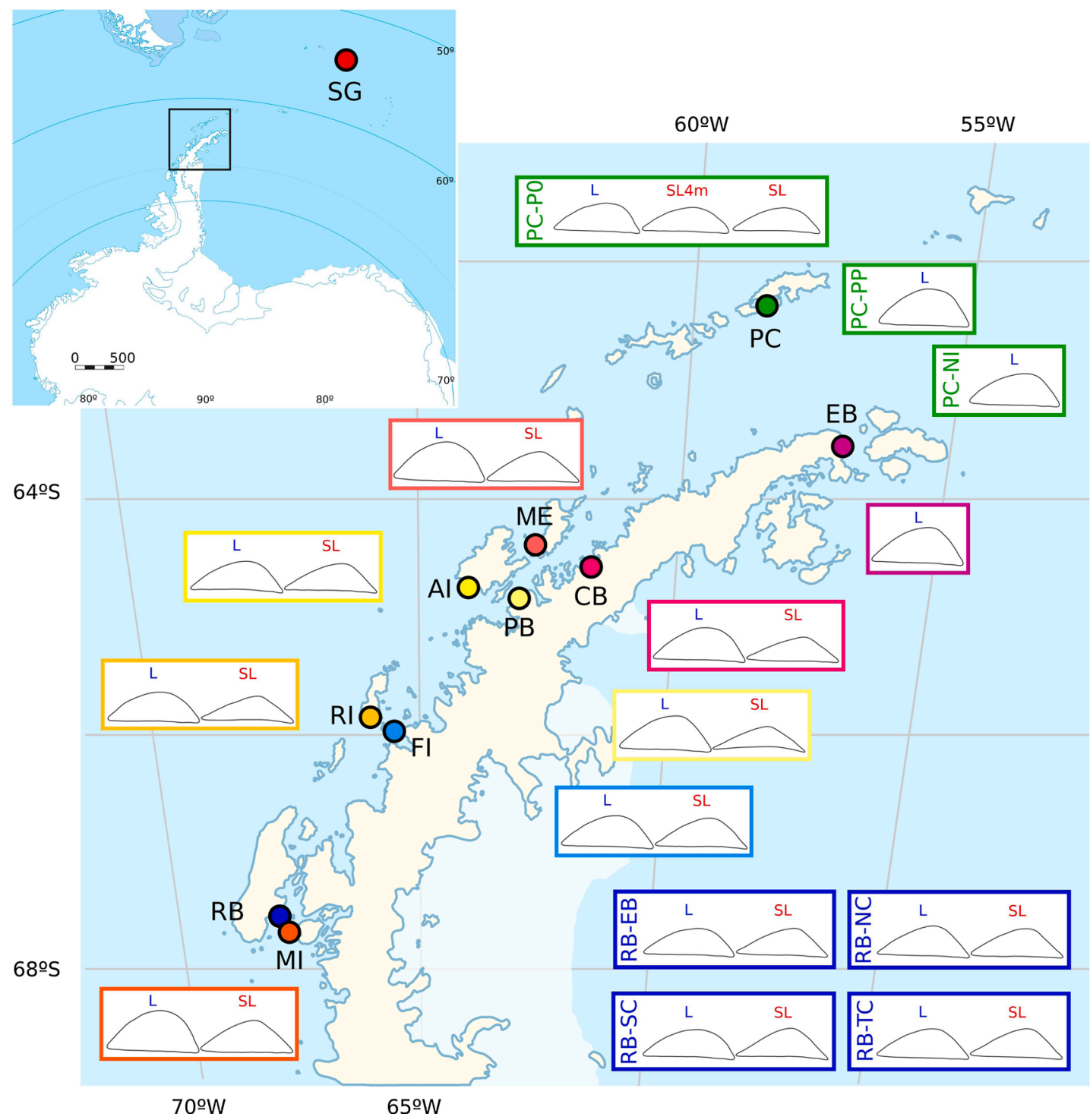

Fig. 2. Samples sites of $N$. concinna in Antarctica. The mean shell shape of the first principal component in lateral view resulting from Elliptic Fourier analysis (EFA) is shown in each locality for Littoral and Sublittoral ecotypes. No shell shape is shown for the sample sites SG and PC-P since they were included in the genetic analysis but not in the morphometric study. PC-PP, PC-NI and EB present only L samples; PC-P0 was sampled at three depths (for more details, see Table 1). SG: South Georgia Islands; PC: Potter Cove; PC-P0: Peñón Cero, Potter Cove; PC-PP: Peñón de Pesca, Potter Cove; PC-NI: New Island, Potter Cove; PC-P: Pinitos, Potter Cove; EB: Esperanza Bay; ME: Melchior Island; CB: Charlotte Bay; AI: Anvers Island; PB: Paradise Bay; RI: Renaud Island; FI: Fish Island; RB: Ryder Bay; RB-EB: East Beach, Ryder Bay; RB-SC: South Cove, Ryder Bay; RB-NC: North Cove, Ryder Bay; RB-TC: Tiny Cove, Ryder Bay; MI: Mikkelsen Island. L: littoral zone; SL: sublittoral zone; SL 4m: sublittoral $4 \mathrm{~m}$ depth (only for PC-P0).

2010). Shells of adult specimens were digitised on lateral and dorsal views as described in Castillo et al. (2019). Images were binarised and afterwards processed with SHAPE software v. 1.3 (Iwata and Ukai, 2002). The closed curve of each limpet shell was decomposed into a sum of 15 harmonically related ellipses as it described in de Aranzamendi et al. (2010). A principal component analysis (PCA) was performed on EFA coefficients to reduce the dimensionality of the data set; individual scores were averaged to plot the samples according to sample sites and depths.

The visualisations of shape variation were conducted following the procedure proposed by Furuta et al. (1995) and implemented in SHAPE (Iwata and Ukai, 2002). To assess potential correlation of the shape variation between lateral and dorsal views of both ecotypes (L and SL) throughout their geographical distribution, we performed Two-block Partial Least Squares analyses (2BPLS; Rohlf and Corti, 2000). A total of 1,000 permutations were used for the whole data set and each ecotype separately with the two.b.pls function of the geomorph package v. 3.2.1
(Adams and Otárola-Castillo, 2013; Adams et al., 2020) for R v. 4.1.0 (R Development Core Team, 2019).

In order to account for the allometric effect on shell shape, we performed a PCA on three traditional linear measurements of the shell to obtain a shell size proxy. The shell length (the largest distance between the anterior and posterior ends), shell width (the largest distance perpendicular to the anterior and posterior axis) and shell height (the largest vertical distance from the apex to the shell base) of each individual were measured using a digital calliper with an accuracy of $0.01 \mathrm{~mm}$. The resulting PC 1 , which accounted for $96.97 \%$ of the total variance, suggests little variation in size among individual measurements (see Supplementary material 1). Hereafter, we used PC 1 as a shell size proxy.

\subsection{Parallelism analyses}

To assess the presence of parallelism in phenotypic trajectories, we 
analysed specimens only from the 12 sample sites where both depths were sampled. We excluded Peñón Cero SL 4m (PC-P0 SL 4m) to avoid possible mixing of ecotypes due to the intermediate depth. To reduce the dimensionality of the data, the first three principal components of the lateral view and the first seven principal components of the dorsal one that represented $90.61 \%$ and $90.07 \%$ of the total variance, respectively, were used for the subsequent statistical analyses (PC scores available at https://doi.org/10.6084/m9.figshare.13053296.v1). First, differences in shell shape between the ecotypes were assessed, followed by the analyses of phenotypic trajectories. We tested for shape differences among sample sites and depth (ecotype) controlling for variation of shell size (static allometry) in both lateral and dorsal datasets through multivariate linear models using a random residual permutation procedure in the $\mathrm{R}$ package $R R P P$ v. 0.5 .2 with 10,000 permutations (implemented in the R package geomorph; Collyer and Adams, 2018).

To calculate the contribution of parallel and non-parallel aspects (i. e., those factors that bias phenotypic traits to evolve along not similar trajectories) of specific morphological variables (as quantified by the principal components) to the divergence of both ecotypes within and across sample sites, we used the ANOVA (analysis of variance) test as outlined by Langerhans and DeWitt (2004). This approach allows examining aspects of phenotypic variation associated with the common environmental gradient (ecotype in our study case), unique historical factors (i.e., from unique clade-factors to localized environmental differences; represented by sample site), and unique responses to the gradient (ecotype-sample site interaction) (Langerhans and DeWitt, 2004). The ANOVA assumptions of homogeneity of variances and normality were checked by inspecting diagnostic plots. The ANOVAs were performed for both views using individual principal component (PC) scores. We tested for the extent of parallel and non-parallel (ecotype effect and ecotype $\mathrm{x}$ sample site interaction, respectively) phenotypic divergence of ecotypes across the AP and adjoined islands and the effect of the unique evolutionary history of each ecotype pair (sample site effect) on phenotypic variation across AP. For each PC, the models were as following:

$\mathrm{PC} \sim$ ecotype + sample site + shell size + ecotype $\mathrm{x}$ sample site + ecotype $\mathrm{x}$ shell size + sample site $\mathrm{x}$ shell size + ecotype $\mathrm{x}$ sample site $\mathrm{x}$ shell size

We used the etas $s q$ function in R package sjstats $v$. 0.17.9 (Lüdecke, 2020 ) to estimate the effect size (Wilk's partial $\eta^{2}$ ) of each model term for PC scores. Therefore, PCs, for which the ecotype term has the largest effect size in relation to the other two terms (sample site; ecotype $\mathrm{x}$ sample site interaction), would be highly parallel between ecotypes across Antarctica. Those PCs, for which the ecotype term explains more variation than the interaction terms, but not more than the sample site term, would be to some degree parallel but are strongly influenced by differences in local conditions. All models (multivariate model using a random residual permutation procedure and ANOVA) were analysed using type III sums of squares.

To quantify the level and deviation of parallelism across replicate ecotypes, we carried out a complementary phenotypic trajectory analysis (PTA; Collyer and Adams, 2013) based on all PCs combined (lateral view: PC 1 - PC 3; dorsal view: PC 1 - PC 7). The PTA was conducted using the trajectory.analysis function in RRPP after fitting linear models with 10,000 permutations in the lm.rrpp function. The significance of differences in trajectory lengths ( $\Delta \mathrm{L}_{\mathrm{p}}$ : differences in the magnitude of phenotypic variation) and trajectory directions ( $\theta_{\mathrm{p}}$ : differences in the direction of phenotypic variation) was calculated. It is supposed that completely parallel ecotype-pairs between localities diverged to the same extent and in the same direction ( $\Delta \mathrm{L}_{\mathrm{P}}$ and $\theta_{\mathrm{P}}$ not different from zero) (see Adams and Collyer, 2009; Stuart et al., 2017 for more details). Finally, to test for a geographic distance effect (mainly latitudinal) on the degree of parallelism across replicate ecotypes, we performed Mantel tests with 999 permutations in PAST v. 3.26 (Hammer et al., 2001). Both views (lateral and dorsal) were analysed using $\Delta \mathrm{L}_{\mathrm{P}}$ and $\theta_{\mathrm{P}}$ matrices. Geographic distances between sample sites were obtained following the shortest coastline distance.

\section{Results}

\subsection{Genetic variability and identification of evolutionary lineages}

GenBank sequences (662 bp) and the newly sequenced ones (597$675 \mathrm{bp}$ ) were aligned and trimmed to a common length (586 bp). We obtained 29 COI haplotypes with low levels of polymorphism along more than 2,000 km with different geographical barriers. Seven haplotypes were newly found in this study (H18, H19, H21, H22, H25, H28, H29), and six coincided with previously described haplotypes (González-Wevar et al., 2013). A total of 16 haplotypes were not registered in our samples and were included from the previous study (González-Wevar et al., 2013, H2, H5, H7, H8, H9, H10, H11, H12, H13, $\mathrm{H} 14, \mathrm{H} 15, \mathrm{H} 16, \mathrm{H} 20, \mathrm{H} 23, \mathrm{H} 26, \mathrm{H} 27)$. Only 30 variable sites $(5.12 \%)$ with eight parsimony informative sites $(1.36 \%)$ were detected. The overall mean distance (p-distance) between haplotypes was $0.005 \pm 0.001$ (SE), and the maximal genetic distance between haplotypes (data not shown) was 0.01 (between $\mathrm{H} 27$ and $\mathrm{H} 28$, both unique haplotypes from distant areas). The median-joining network obtained for $N$. concinna showed a star-like topology (Fig. 3A). The two more frequent haplotypes (H1 with 77 individuals; $\mathrm{H} 17$ with 21 individuals) were shared in sample sites along all study areas from SG to MI. Besides, these two haplotypes are present in the L and SL samples, indicating the presence of a unique evolutionary lineage (Fig. 3B). Samples from L and SL ecotypes shared four haplotypes, five haplotypes resulted exclusively for L and two for SL.

\subsection{Shape variation between littoral and sublittoral shells along AP}

The scatter plot of PC 1 vs. PC 2 (80.85 and 5.91\% of the total variation, respectively) from the lateral view shows that both PCs together separate samples according to depth (Fig. 4 A, C). The PC 1 is clearly related to the variation in relative shell height (see the reconstruction of contours in Fig. 4 lateral view), whereas the taller and more globose shapes are related to L samples and flatter and longer individuals are related to SL samples. These characteristics are clear in each sample site, but are most evident in PC-P0, CB, ME, PB, AI and MI. These shape differences are subtle in RI and FI. In some sample sites, there is no marked difference in relative height between the depths, as in the case of RB-EB, RB-TC and RB-SC. Along PC 2, all sample sites show the same pattern where the shell apex is more central and also pointer in the SL samples while the L one presents a lower apex that is slightly shifted towards the anterior part of the shell. However, this PC explains little of the total variation in shape. Interestingly, PC-POSL4m that could have a mixture of both ecotypes due to the intermediate depth is placed between the L and SL samples of PC-P0 in PC 2.

In the dorsal view plot, individuals are separated according to their relative width, but the ecotypes (L and SL) were not clearly differentiated (PC 1 and PC 2 explain $51.14 \%$ and $24.62 \%$ of the total variation, respectively; Fig. 4 B, D). Nevertheless, taking into account the mean shape of the depths in each sample site, $L$ individuals were on average more elongated than SL ones, which tend to be more rounded along PC 1. These differences are evident in most sample sites except in $\mathrm{CB}$ and ME where differences are subtle; in PC-P0 the opposite was observed. PC 2 shows a continuous range between an elliptical and a pear-shaped outline. However, when analysing the mean shape in each sample site, $\mathrm{L}$ and SL are slightly more pear-shaped. Interestingly, the three depths sampled in PC-P0 were separated from the rest, being generally more elliptical in their dorsal view.

The 2BPLS showed that the patterns of shape variation between lateral and dorsal views in this limpet are slightly but significantly correlated ( $\mathrm{r}-\mathrm{PLS}=0.333 ; \mathrm{P}=0.001$ ). When depth samples are treated separately, the shape of both views in L individuals does not covariate (r- 


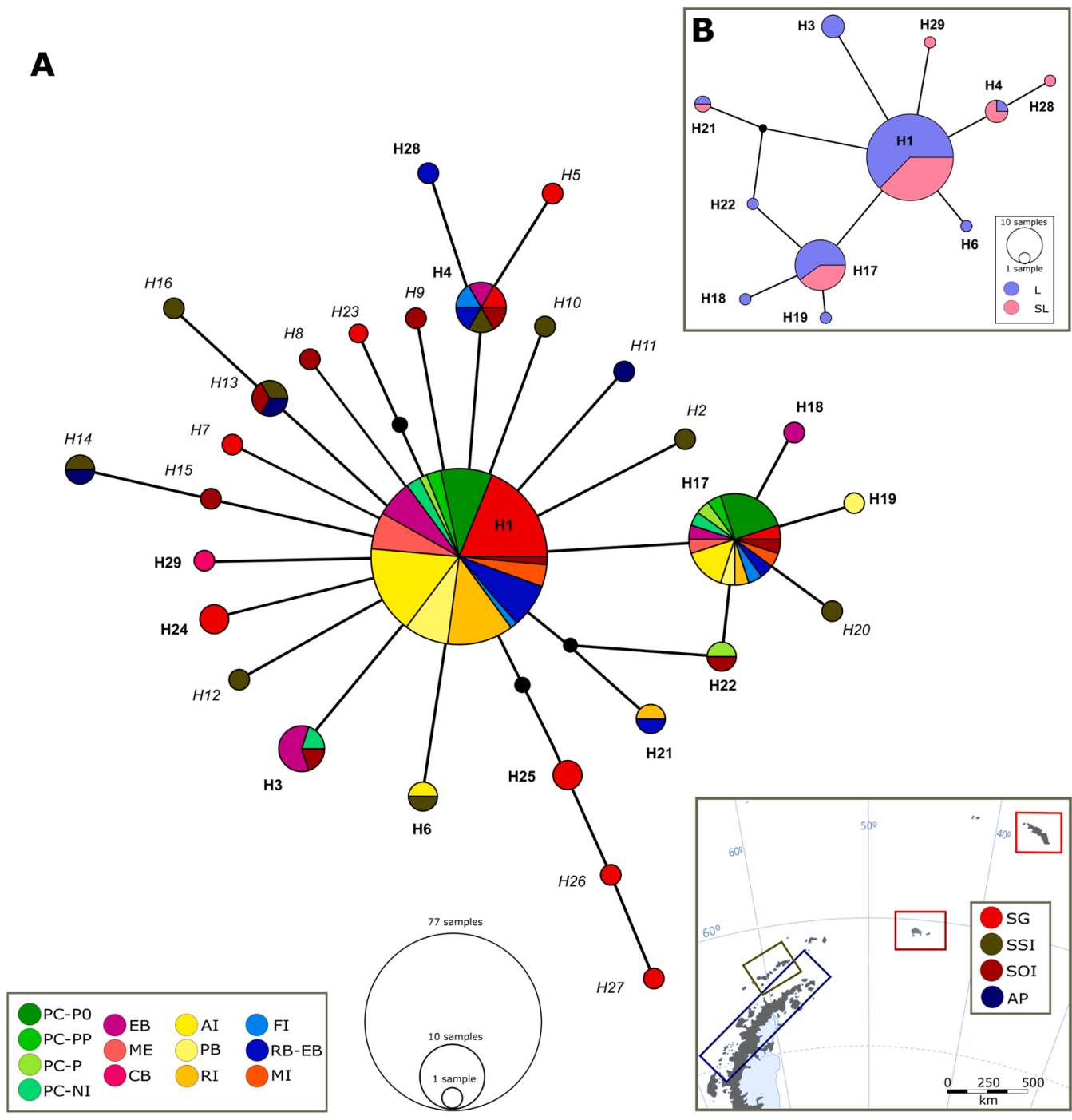

Fig. 3. Haplotype network of COI mitochondrial DNA sequence data from $N$. concinna. A. Haplotype network showing the relationships among 29 haplotypes (whole data set). Haplotypes from GenBank are included in this analysis. The location of sample sites of González-Wevar et al. (2016) that coincides with part of our sampling areas are shown in the map insert (see Fig. 1). Some haplotypes were not found in our study but in González-Wevar et al. (2016), and are included anyway in our study as unique haplotypes and are highlighted in italics. B. Haplotype network classifying the individuals according to depth from the South Shetland Islands and Antarctic Peninsula (our data set excluding SG samples). In both networks, circle sizes are proportional to the number of total sequences with each haplotype. The colours within circles indicate the proportion of specimens of each sample site per haplotype. Black circles are vectors representing ancestral or unsampled haplotypes. We use the following abbreviation: SSI: South Shetland Islands, SG: South Georgia Islands, SOI: South Orkneys Islands, AP: Antarctic Peninsula. For the other abbreviations see Fig. 2.
$\mathrm{PLS}=0.151 ; \mathrm{P}=0.361$ ), whilst lateral shape is slightly correlated with dorsal view in SL limpets $\quad(r-P L S=0.396 ; \quad P=0.001 ; \quad$ Figure Supplementary material 2).

Results from multivariate linear models for shape variation in lateral view showed effects related to sample sites, ecotype, shell size and the interaction term between ecotype and sample site, which accounted for $2.94 \%, 1.84 \%, 0.54 \%$, and $3.77 \%$ of the total variation in lateral view, respectively (Table 2). We observed significant differences in dorsal shape for the main effects related to sampling sites and ecotype that accounted for $7.79 \%$ and $0.53 \%$, respectively (Table 2 ).

\subsection{Phenotypic parallelism along the AP}

The assessment of effect size values on phenotypic divergence in particular shape variables (Table 3 ) indicated variation mainly due to ecotype (parallel) divergence (PC 1 and PC 2 of lateral view), nonparallel divergence (ecotype x sample site interaction term; PC 5 and PC 7 of dorsal view), sampling site variation (PC 1 and PC 2 of dorsal view) and with a similar contribution of sampling site effect and nonparallel divergence (PC 3 of lateral view, and PC 4 and PC 6 of dorsal view; Table 3; see ANOVA results in Table Supplementary material 3). The relationship between parallel (ecotype) and non-parallel (ecotype $\mathbf{x}$ sample site interaction term) demonstrated that three of the ten PCs show stronger parallel than non-parallel divergence (PC 1 and PC 2 of lateral view, and PC 2 of dorsal view; Fig. 5A).
The PTA approach allows estimating the extent of multivariate phenotypic parallelism, taking into account the difference in phenotypic trajectory length $\left(\Delta \mathrm{L}_{\mathrm{P}}\right)$ and the direction of phenotypic trajectories (i.e., the angle; $\theta_{\mathrm{P}}$ ). In lateral view, we found that the magnitude and direction of phenotypic variation between ecotypes were variable across replicates but mostly not significantly $\left(\Delta \mathrm{L}_{\mathrm{p}}\right.$ : mean $=0.0272 \pm 0.0182$ $\mathrm{SD}, \quad$ median $=0.0256 ; \quad \theta_{\mathrm{p}}: \quad$ mean $=47.658^{\circ} \quad \pm 23.806 \mathrm{SD}$, median $=47.873^{\circ}$ ). The magnitude of divergence varied between 0.001 and 0.074 , with $86.4 \%$ of the ecotype comparisons being not significantly different ( $P>0.05$; Fig. 5B, Table Supplementary material 4$)$. $98.4 \%$ of ecotype-pairs were significantly parallel according to the direction of phenotypic trajectories, ranging from $7.229^{\circ}$ to $115.86^{\circ}$. The higher angles obtained (although not significant) belong to PC-P0, and RB-EB, RB-SC, RB-NC and RB-TC with other sample sites $\left(\theta_{\mathrm{P}}>65^{\circ}\right)$, even with MI, this latter located in Ryder Bay, close to Rothera Research Station. From all comparisons, only ME and MI are found to be not parallel $\left(\theta_{\mathrm{P}}=70.71^{\circ}, P=0.018\right)$ but with a not significantly different phenotypic trajectory length $\left(\Delta \mathrm{L}_{\mathrm{P}}=0.028, P=0.154\right)$. Completely parallel ecotypes were observed in $84.85 \%$ of the comparisons among sample site pairs; this is they showed both $\Delta \mathrm{L}_{\mathrm{P}}$ and $\theta_{\mathrm{P}}$ not different from zero. Using the same approach in the dorsal view, most of the ecotypepairs were significantly parallel (65.15\% with $\Delta \mathrm{L}_{\mathrm{P}}$ and $\theta_{\mathrm{P}}$ not significant from zero, $P>0.05$; Fig. 5B, Table Supplementary material 5). In general, the magnitude of the divergence between sample sites was smaller in dorsal than in lateral view $\left(\Delta \mathrm{L}_{\mathrm{P}}\right.$ : mean $=0.0099 \pm 0.0069 \mathrm{SD}$, 
Lateral EFA

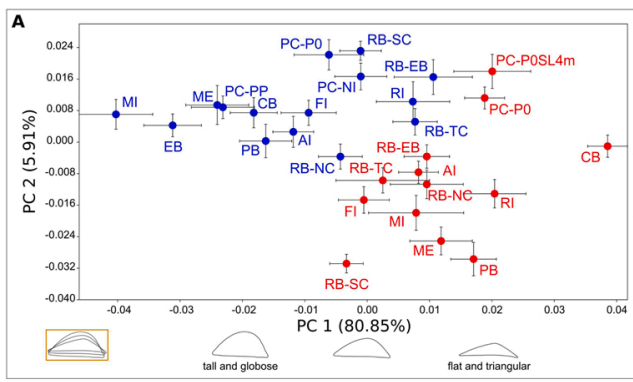

Dorsal EFA

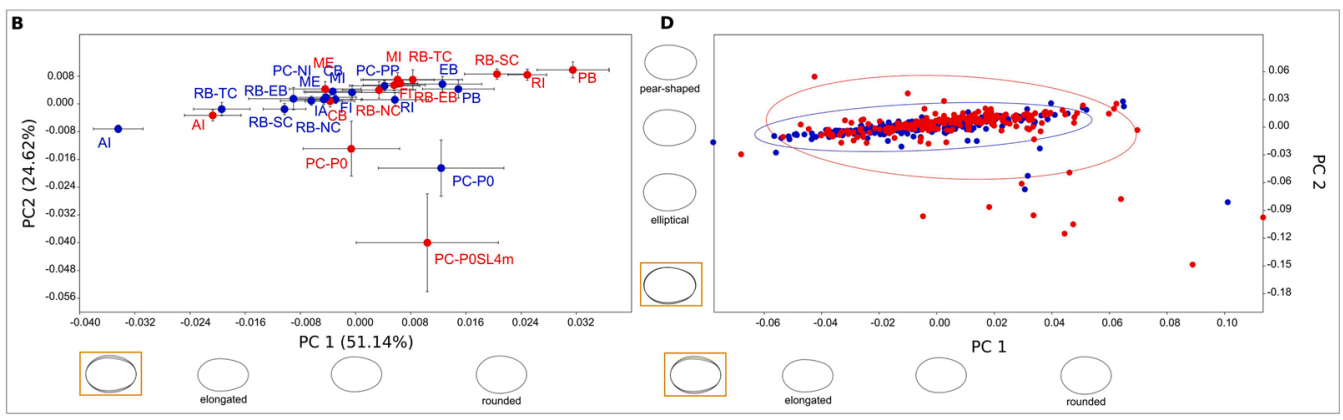

Fig. 4. Plots of principal component analyses in $N$. concinna according to sample sites and depths (A, B); and only depth (C, D). Mean, +2 and -2 standard deviations (SD) shell shapes (reconstructed outlines) along each principal component are shown; the three overlapping shapes are shown for each PC to indicate the total range of variation. In (A) and (B), points represent the mean and the whiskers the standard errors (SE) of each sample site. For abbreviations see Fig. 2. The 95\% confidence ellipses for the littoral and sublittoral samples are shown. Percentages of explained variance for each axis are in parentheses.

Table 2

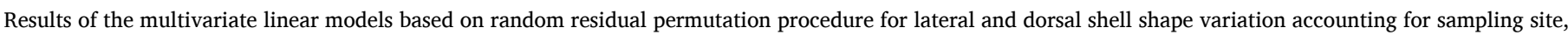

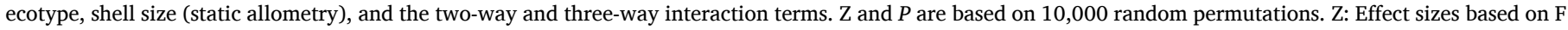
distributions. P values in bold were significant with an $\alpha$ of 0.05 .

\begin{tabular}{|c|c|c|c|c|c|c|c|}
\hline Source of variance & $\mathrm{df}$ & Sum sq & Mean sq & $\mathrm{R}^{2}$ & $\mathrm{~F}$ & $\mathrm{Z}$ & $P$ \\
\hline \multicolumn{8}{|l|}{$\underline{\text { Lateral }}$} \\
\hline$\overline{\text { sample site }}$ & 11 & 0.0155 & 0.0014 & 0.0294 & 2.0589 & 2.7343 & 0.0014 \\
\hline ecotype & 1 & 0.0097 & 0.0097 & 0.0184 & 14.1413 & 3.0673 & $<0.0001$ \\
\hline shell size & 1 & 0.0028 & 0.0028 & 0.0054 & 4.1396 & 1.7795 & 0.0122 \\
\hline sample site $\mathrm{x}$ ecotype & 11 & 0.0199 & 0.0018 & 0.0377 & 2.6416 & 3.6905 & $<0.0001$ \\
\hline sample site $\mathrm{x}$ shell size & 11 & 0.0079 & 0.0007 & 0.0151 & 1.0596 & 0.3452 & 0.3711 \\
\hline ecotype $\mathrm{x}$ shell size & 1 & 0.0018 & 0.0018 & 0.0034 & 2.6106 & 1.3553 & 0.0597 \\
\hline sample site $\mathrm{x}$ ecotype $\mathrm{x}$ shell size & 11 & 0.0073 & 0.0007 & 0.0139 & 0.9722 & 0.017 & 0.5139 \\
\hline residuals & 362 & 0.2482 & 0.0007 & 0.47 & & & \\
\hline total & 409 & 0.5279 & & & & & \\
\hline \multicolumn{8}{|l|}{ Dorsal } \\
\hline$\overline{\text { sample site }}$ & 11 & 0.0321 & 0.0029 & 0.0779 & 4.1116 & 4.3818 & 0.0002 \\
\hline ecotype & 1 & 0.0022 & 0.0022 & 0.0053 & 3.0753 & 1.7461 & 0.036 \\
\hline shell size & 1 & 0.0015 & 0.0015 & 0.0037 & 2.1263 & 1.2728 & 0.0997 \\
\hline sample site $\mathrm{x}$ ecotype & 11 & 0.0089 & 0.0008 & 0.0218 & 1.1505 & 0.6142 & 0.2667 \\
\hline sample site $\mathrm{x}$ shell size & 11 & 0.0089 & 0.0008 & 0.0217 & 1.1454 & 0.5723 & 0.2736 \\
\hline ecotype $\mathrm{x}$ shell size & 1 & 0.0001 & 0.0001 & 0.0003 & 0.1674 & -1.5214 & 0.9378 \\
\hline sample site $\mathrm{x}$ ecotype $\mathrm{x}$ shell size & 11 & 0.01 & 0.0009 & 0.0243 & 1.2809 & 0.9825 & 0.1626 \\
\hline residuals & 362 & 0.2568 & 0.0007 & 0.6234 & & & \\
\hline total & 409 & 0.4119 & & & & & \\
\hline
\end{tabular}

median $=0.0083$ ) with RB-CS and RB-TC showing significant phenotypic trajectories length with most of the sample sites. Contrarily, the direction of phenotypic trajectories was higher $\left(\theta_{\mathrm{p}}\right.$ : mean $=62.167^{\circ} \pm$ 39.814 SD, median $=42.81^{\circ}$ ) with highly parallel values between $\mathrm{AI}$ and RB-SC $\left(\theta_{\mathrm{P}}=10.673^{\circ}, P=0.992\right)$ to non-parallel in PC-P0 and RBEB comparison $\left(\theta_{\mathrm{P}}=135.94^{\circ}, P=0.008\right)$. Unsurprisingly, PC-P0 showed phenotypic non-parallelism with almost all sample sites $\left(\theta_{\mathbf{P}}\right.$ between $90.29^{\circ}-135.94^{\circ}$ ). Results from the Mantel tests showed no correlation between geographic distances and PTA for lateral view $(R=$ $-0.103, P=0.765$ for $\Delta \mathrm{L}_{\mathrm{P}} ; R=-0.001, P=0.408$ for $\theta_{\mathrm{P}}$ ). In the dorsal view, a positive correlation was found between geographic distances and the direction of phenotypic trajectories $(R=0.552, P=0.007$ for $\left.\theta_{\mathrm{P}}\right)$, while there was no relation for the magnitude of the divergence $(R=$ $-0.102, P=0.699$ for $\left.\Delta \mathrm{L}_{\mathrm{P}}\right)$.

\section{Discussion}

The Antarctic limpet $N$. concinna inhabits two contrasting habitats, littoral and sublittoral zones, where it forms different ecotypes coexisting throughout its whole distribution range. This work addresses the extent to which ecological phenotypic divergence is repeatable in this species. Overall, we observed that, despite some variable extent, this Antarctic species showed a marked pattern of parallel morphological divergence between ecotypes along its distribution.

\subsection{Replicated Littoral and Sublittoral ecotypes along the AP}

The registered shell shape of ecotypes in this work matched previous descriptions (Nolan, 1991; Brêthes et al., 1994; de Aranzamendi et al., 2010; Castillo et al., 2019; Lomovasky et al., 2020). Differences between 
Table 3

Effect sizes (partial $\eta^{2}$ ) for each model term from principal components (PC) of the EFA analyses based on lateral and dorsal views.

\begin{tabular}{|c|c|c|c|c|c|c|c|c|}
\hline PC & $\begin{array}{l}\% \text { explained } \\
\text { variance }\end{array}$ & $\begin{array}{l}\text { sample } \\
\text { site }\end{array}$ & ecotype & $\begin{array}{l}\text { shell } \\
\text { size }\end{array}$ & $\begin{array}{l}\text { sample site } \mathrm{x} \\
\text { ecotype }\end{array}$ & $\begin{array}{l}\text { sample site } \mathrm{x} \text { shell } \\
\text { size }\end{array}$ & $\begin{array}{l}\text { ecotype } \mathrm{x} \text { shell } \\
\text { size }\end{array}$ & $\begin{array}{l}\text { sample site } \mathrm{x} \text { ecotype } \mathrm{x} \text { shel } \\
\text { size }\end{array}$ \\
\hline $\begin{array}{l}\text { PC } 1 \\
\quad \text { lateral }\end{array}$ & 80.85 & 0.225 & 0.33 & 0.222 & 0.2 & 0.022 & 0 & 0.023 \\
\hline $\begin{array}{l}\text { PC } 2 \\
\text { lateral }\end{array}$ & 5.92 & 0.213 & 0.38 & 0.164 & 0.177 & 0.012 & 0.001 & 0.019 \\
\hline $\begin{array}{l}\text { PC } 3 \\
\text { lateral }\end{array}$ & 3.85 & 0.17 & 0.087 & 0 & 0.144 & 0.019 & 0.011 & 0.047 \\
\hline PC 1 dorsal & 51.14 & 0.345 & 0.071 & 0.095 & 0.075 & 0.046 & 0.006 & 0.047 \\
\hline PC 2 dorsal & 24.62 & 0.197 & 0.029 & 0.005 & 0.015 & 0.041 & 0 & 0.026 \\
\hline PC 3 dorsal & 4.44 & 0.09 & 0.002 & 0.004 & 0.025 & 0.037 & 0.003 & 0.022 \\
\hline PC 4 dorsal & 2.98 & 0.034 & 0.001 & 0 & 0.032 & 0.026 & 0.01 & 0.026 \\
\hline PC 5 dorsal & 2.70 & 0.068 & 0.005 & 0 & 0.032 & 0.038 & 0.001 & 0.025 \\
\hline PC 6 dorsal & 2.20 & 0.04 & 0.021 & 0.001 & 0.033 & 0.03 & 0.002 & 0.011 \\
\hline PC 7 dorsal & 1.99 & 0.047 & 0.038 & 0.012 & 0.094 & 0.033 & 0.001 & 0.056 \\
\hline
\end{tabular}

A

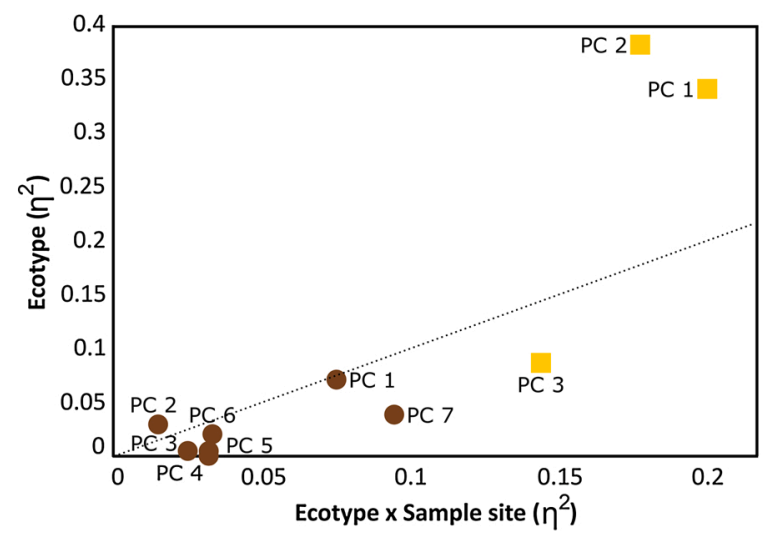

B

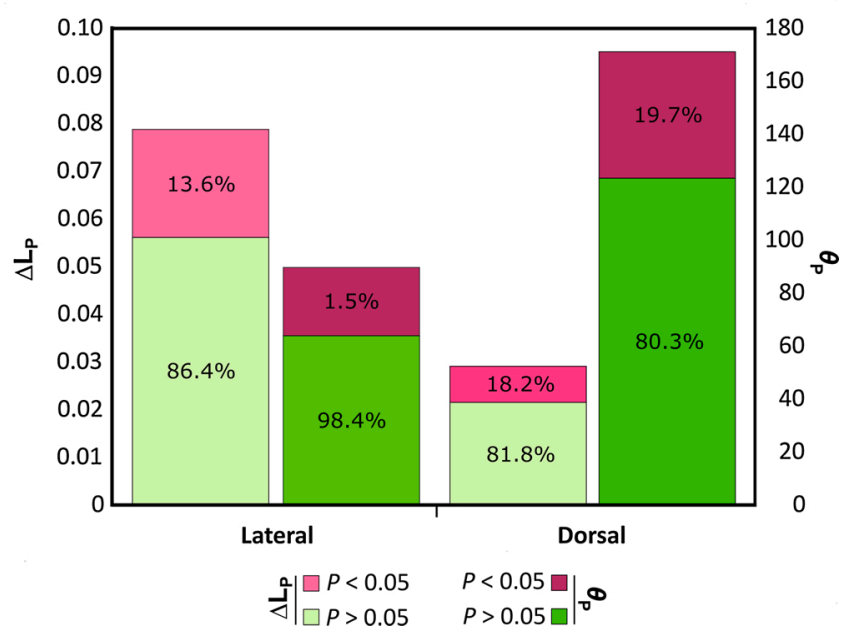

Fig. 5. Results of phenotypic parallelism analyses in N. concinna. A. Effect sizes (partial $\eta^{2}$ ) of the ecotype and 'ecotype $\mathrm{x}$ sample site' interaction terms for PC 1 to PC 3, lateral view (squares) and PC 1 to PC 7, dorsal view (circles). The dotted line represents the regression line. B. Comparison of the phenotypic trajectory analysis based on PCs of lateral and dorsal views. Differences in significant and not significant trajectory lengths $\left(\Delta \mathrm{L}_{\mathrm{P}}\right)$ and angles $\left(\theta_{\mathrm{P}}\right)$ are shown under the hypothesis of equal phenotypic trajectories. The percentages of comparisons between sample sites that are statistically significant or not significant are indicated on bars.

ecotypes were generally greater considering the lateral profile. The $\mathrm{L}$ individuals were relatively taller with the apex towards the anterior part of the shell and presented a globose shape, while the SL limpets had flatter and triangular shells with a more central shell apex. In the case of the dorsal shape, we can generalise that $\mathrm{L}$ and SL individuals tended to be more pear-shaped than elliptical. These ecotypes were repeated throughout almost all the different sampled sites along the AP. Nonetheless, ecotype differences in shape are not evident in all cases. Lateral shape showed subtle differences in four sample sites located in Ryder Bay (RB-EB, RB-SC, RB-NC, RB-TC). Hoffman et al. (2010), in a study performed at Ryder Bay and based on EFA of dorsal view from shells, suggested that the distinction in $L$ and SL ecotypes could be artificial and instead there would be a continuous cline in shell shape from the littoral zone down to deeper waters. Despite the fact that we could not make an analysis considering the clinal depth gradient, our EFA results of dorsal view showed slight differences between L and SL individuals at the four sample sites of Ryder Bay station. The EFA results of lateral view showed that the four sampling sites in Ryder Bay are among the ecotype-pairs with the smallest differences between L and SL forms that we detected in this study (see the lateral contour reconstruction of shells; Fig. 1). Furthermore, a possible cline change between littoral and sublittoral zones does not rule out the existence of L and SL ecotypes. In fact, cline analysis has been proposed as one of the most direct ways of measuring the strength of selection in nature given its ability to identify the tension between selection and gene flow (Kawecki and Ebert, 2004; Mullen and Hoekstra, 2008). Therefore, although greater shape differentiation was detected between L and SL samples, there were differences among sample sites as well. Indeed, other works using traditional morphometrics or EFA showed differences between L and SL within localities but also between samples of the same depth from different locations (Beaumont and Wei, 1991; de Aranzamendi et al., 2008, 2010; González-Wevar et al., 2011a). These variations among sample sites could be due to a variation in shape across sites with local environmental variables or other evolutionary forces such as genetic drift or gene flow acting on phenotypes (Stuart et al., 2017; see next section).

The different parts of an individual that cause variation in fitness have the potential to evolve over time. Considering that such variation can be under different selective pressures or even under different evolutionary forces (i.e., genetic drift; Klaczko et al., 2015; Caetano and Harmon, 2019), we examined the degree of phenotypic integration between lateral and dorsal view shape of shells. We observed that shell shape variation of the views was slightly correlated in the SL limpets, indicating that shell shape is evolving to some degree as an integrated unit. Contrarily, shells from L displayed a low and not significant shape covariation, possibly owing to different evolutionary forces acting on the studied traits such as local selection pressures (Peck et al., 2006; Marcías et al., 2017). Actually, integration is expected to diminish when traits are under different selection pressures (Adams et al., 2017; Sherratt et al., 2017). However, even if there is phenotypic integration, different selective components could be acting in the same direction on each trait. In $N$. concinna the littoral population presents slower growth and less variable growth rates, mainly related to shell length and width, 
than sublittoral one, reflecting either a limitation of feeding time or an energy gap for shell growth due to the costs for migratory movements and stress defence (Lomovasky et al., 2020). The lack or low correlation between the lateral and dorsal views in L and SL individuals suggests how the ecology of organisms affects their evolutionary morphological integration and how environmental pressures drive their shell shape (Melo and Marroig, 2015; Tsuboi et al., 2015). This aspect needs further evaluation by canalization assessment (i.e., the tendency of developmental processes to follow particular trajectories, despite external and internal perturbations).

\subsection{Potential forces driving or restraining phenotypic parallelism in N. concinna}

We found low COI genetic variability in almost the complete distribution range of this limpet. These values are similar to previously reported ones using the same molecular marker (González-Wevar et al., 2013) and lower than the ones obtained in Patagonian and subantarctic congener species (de Aranzamendi et al., 2011; González-Wevar et al., 2011b, 2012, 2016). Interestingly, we observed a unique evolutionary lineage including samples from both L and SL depths and several haplotypes shared between ecotypes, suggesting a recent origin for many of their haplotypes. As has been proposed in numerous studies, climate changes that occurred in the Quaternary are considered to have strongly affected the distribution, abundance, and current genetic structure of organisms in Antarctica (e.g., Raupach et al., 2010; Díaz et al., 2018; Lau et al., 2020). In fact, the lack of genetic structure observed in mtDNA for $N$. concinna along AP could be explained by its relatively recent recolonisation of the area from peri-Antarctic refuges like South Georgia Islands after its eradication of shallow waters from Antarctica due to glaciations and subsequently increased ice disturbance in coastal environments (González-Wevar et al., 2013).

By sharing mtDNA evolutionary lineage and thriving on divergent habitats, L and SL ecotype-pairs could be the result of remarkably strong incidence of parallel evolution. Since we could not perform a parallelism analysis including genetic data due to the low resolution of the molecular marker used for this study- indeed it would require the analysis of genomic data (i.e., single-nucleotide polymorphism, SNP)- we could not discard the presence of phenotypic plasticity. In fact, phenotypic plasticity is sometimes overlooked in studies of parallel evolution. However, recent evidence suggests that plasticity contributes in an adaptive way to parallelism in nature since plasticity often enhances adaptive phenotypic divergence (Oke et al., 2016). For this reason, we focused our discussion on parallel morphological divergence in this limpet and hypothesized about potential forces or scenarios explaining it.

We detected considerable variation in the extent of parallelism for specific variables (i.e., PC axes) and overall shape (based on trajectory analyses) across independently replicated limpet's ecotype-pairs. Relative shell height (lateral PC 1, 80.8\%), relative position of the shell apex (lateral PC 2, 5.91\%) and relative elliptical/pear-shaped outline (dorsal PC 2, 24.62\%) showed remarkable parallelism instead of nonparallelism. Changes in height and apex position of shells (represented, in part, by PC 1 and PC 2 of the analysis based on lateral view) have been suggested to be a consequence of the wave action and resistance to higher temperature oscillations and air exposure during low tide suffered by the littoral limpets (Berry and Rudge, 1973; Shabica, 1976; Nolan, 1991; Weihe and Abele, 2008). Consequently, these traits are likely to be under constant natural selection pressure (see Castillo et al., 2019) and are vital for the adaptation to the littoral zone. The variation between elliptical to pear-shaped shells has been suggested to be influenced by predation pressure by means of directional selection (Nolan, 1991; Castillo et al., 2019). Notwithstanding that seagulls predate on limpets along the littoral zone of AP, it has been hypothesised that the abundance and, in consequence, predation intensity could vary among sample sites (Castillo et al., 2019), which could be explained by the high effect size value of sample site effect in our results. In contrast, relative shell width (represented, in part, by dorsal PC 1; 51.14\%) demonstrated weak parallelism among ecotype replicates across Antarctica, evidencing other agents acting on the convergence of shell shape. Considering PTA results, completely parallel ecotype-pairs (concerning both magnitude and direction) among sample sites were detected in $84.85 \%$ of lateral and $65.15 \%$ of dorsal view comparisons. Besides, the proportion of parallel divergence in direction $(86.4 \%$ in lateral view, $81.8 \%$ dorsal one) and magnitude (98.4\% lateral view, $80.3 \%$ dorsal) was considerably high, suggesting that $L$ and SL ecotypes have diverged to a high degree in the same phenotypic direction along the AP.

However, the direction and magnitude of this divergence were not always highly parallel between replicate ecotype-pairs. Independent populations in similar environments always show some differences; to wit, some non-parallel evolution is present (Bolnick et al., 2018). The direction of the morphological divergence among sample sites could be less parallel between ecotype-pairs in habitats whose differences are less parallel due to environmental heterogeneity between sites that add to deviations from phenotypic parallelism (Stuart et al., 2017). As ecotypes are discrete categories, the habitats (littoral or sublittoral) could include considerable variation between sites, either in variation or in the presence of relevant ecological factors (Kaeuffer et al., 2012; Oke et al., 2017). In our study, PC-P0 resulted non-parallel compared with most sample sites in dorsal view, whilst the same happened with MI in lateral shell view. Hamilton et al. (2020) demonstrated that two stressors act as different selective forces moulding the shell of Cellana exarata (Nacellidae). They found phenotypes associated with thermal avoidance in islands without human harvesting, while the prevalence of maladaptive morphotypes for thermal avoidance on islands with high predation pressure suggests that predation is a stronger selective force, driving adaptive trade-offs in shell shape and colour. Hence, differences between ecotype-pairs could be due to how stressors affect the littoral and sublittoral in each sample site along the distribution range (Smith et al., 2012; Grange and Smith, 2013; Gutt et al., 2015; Castillo et al., 2019). The intensity of stressors like wave action or ice crushing (determined by oceanographic conditions; Deregibus et al., 2017; Barnes et al., 2018), desiccation (influenced by air temperature; Comiso, 2000; Cook et al., 2016), and avian predation (depending on the abundance of seagulls; Castillo et al., 2019; but see Vervust et al., 2007; Hammerschlag et al., 2018) likely vary to some degree along the AP. Indeed, when testing for a distance effect along the latitudinal gradient, we observed that the direction of divergence of ecotype-pairs in dorsal view, often associated with variation in the direction of selection (Stuart et al., 2017), increased as a function of the distance separating sample sites suggesting the presence of factors changing with distance and influencing shaping adaptation.

Alternatively, these deviations from phenotypic parallelism might have a genetic basis since genetic variation among populations can bias responses to selection (Kaeuffer et al., 2012; Bolnick et al., 2018). Among the potential genetic effects, we can name that populations might have different genomic architectures favouring distinct evolutionary trajectories (Stuart et al., 2017; Jacobs et al., 2020), chromosomal inversions or new mutations could happen in different populations modifying genetic sharing (e.g., Chan et al., 2010; Jones et al., 2012) or genetic drift might occur in only some populations (e.g., Elena and Lenski, 2003; Santangelo et al., 2018). Moreover, the phenotypic non-parallelism could reflect variations in gene flow among localities (e.g., Bolnick and Nosil, 2007; Westram et al., 2016). Our results on mtDNA divergence, limited by its conservative resolution at this eco-evolutionary time scale (Zink and Barrowclough, 2008; Allcock and Strugnell, 2012), joined with other works show genetic differentiation among distant populations in $N$. concinna possibly due to significant oceanographic barriers to gene flow (Hoffman et al., 2011; González-Wevar et al., 2013), but also over a fine spatial scale (few km; Hoffman et al., 2012). Interestingly, replicate ecotype-pairs in given environments might experience different gene flow levels than 
populations in other environments, resulting in the magnitude of divergence being differentially constrained (Hendry and Taylor, 2004; Butlin et al., 2014). Thus, although previous genetic studies did not concord (Beaumont and Wei, 1991; de Aranzamendi et al., 2008; Chwedorzewska et al., 2010; Hoffman et al., 2010), the migratory behaviour of the $\mathrm{L}$ individuals and the reproduction of ecotypes occurring spatially separated (Walker, 1972; Brêthes et al., 1994; Clark et al., 2018) still generate multiple questions, and an incipient genetic divergence cannot be ruled out hitherto. Interestingly, at Ryder Bay Littoral individuals have also been found to remain in the littoral during winter, suggesting that not all individuals migrate to the sublittoral (Waller et al., 2006; Obermüller et al., 2011), strengthening the differentiation between littoral and sublittoral individuals due to a more likely reproductive isolation. This Antarctic limpet could follow the steps of other Patellogastropoda that differ partially or completely in their vertical location on wave-exposed shorelines, having adapted to different habitats with a relatively recent phylogenetic divergence like the two sympatric Magellanic limpets, Nacella magellanica and $N$. deaurata (de Aranzamendi et al., 2011; González-Wevar et al., 2017), species of the sibling genus Cellana in Hawaii (Bird et al., 2011) and various species of Patella on the Macaronesian islands (Carreira et al., 2017).

\section{Conclusions}

We registered parallelism in specific traits but also in overall phenotypic divergence across the AP. Furthermore, we observed weak or absent morphological integration between the two shape shell views. This is consistent with the noticeable differences in the magnitude and direction of phenotypic trajectories between shell views, which suggest there are distinct environmental pressures acting on this limpet's shell shape. In summary, our findings suggest phenotypic parallelism in replicated $N$. concinna ecotypes within a unique mtDNA evolutionary lineage but with local conditions acting also on influencing the shell shape. We need further studies addressing environmental variation and fast-evolving molecular markers (Held and Leese, 2007; Peterson et al., 2012) to achieve a more general understanding of how and to what extent multiple evolutionary processes such as selection, genetic drift, gene flow, genetic background and ecological opportunities interact in this limpet. The evidence of repeated morphological divergences in $N$. concinna ecotypes makes it an appropriate model species to address whether parallel evolution represents the principal force shaping these shells.

\section{Funding}

This work was supported by Grants from the Fondo para la Investigación Científica y Tecnológica, Argentina (FONCyT; PICTO2010-0119), Secretaría de Ciencia y Técnica, Universidad Nacional de Córdoba (SECyT UNC; 33620180100077CB) and the EU project IMCONet (Interdisciplinary modelling of climate change in coastal Western Antarctica - network for staff exchange and training; European Science Foundation and Alfred Wegener Institut; FP7 404 IRSES, action no. 319718).

\section{Declaration of Competing Interest}

The authors declare that they have no known competing financial interests or personal relationships that could have appeared to influence the work reported in this paper.

\section{Acknowledgements}

We are grateful to the Instituto Antártico Argentino (IAA) and Dirección Nacional del Antártico (DNA) for logistical support, and to the crew of the sail-ship Sedna IV (2006) during the "Mission Antarctique". We also want to thank the Shallow Marine Survey Group (Islas
Malvinas/Falkland Islands) for providing samples from South Georgia Islands. We thank Santiago Castillo and Micaela Ruiz for their help in cartoon and map design, respectively. Special thanks to Gastón Alurralde and Alvina Lèche for their contributions to the manuscript and to The Group for their support. We are grateful to Dr. Thomas A. Neubauer and an anonymous reviewer for their helpful comments on the manuscript.

\section{Appendix A. Supplementary data}

Supplementary material related to this article can be found, in the online version, at doi:https://doi.org/10.1016/j.zool.2021.125983.

\section{References}

Adams, D.C., Collyer, M.L., 2009. A general framework for the analysis of phenotypic trajectories in evolutionary studies. Evolution 63 (5), 1143-1154. https://doi.org/ 10.1111/j.1558-5646.2009.00649.x.

Adams, D.C., Otárola-Castillo, E., 2013. Geomorph: an R package for the collection and analysis of geometric morphometric shape data. Methods Ecol. Evol. 4 (4), 393-399.

Adams, D.C., Korneisel, D., Young, M., Nistri, A., 2017. Natural history constrains the macroevolution of foot morphology in European plethodontid salamanders. Am. Naturalist 190 (2), 292-297. https://doi.org/10.1086/692471.

Adams, D., Collyer, M., Kaliontzopoulou, A., Baken, E., 2020. Geomorph: Software for geometric morphometric analyses. R package version 3.2.1.

Agrawal, A.A., 2017. Toward a predictive framework for convergent evolution: Integrating natural history, genetic mechanisms, and consequences for the diversity of life. Am. Naturalist 190, S1-S12. https://doi.org/10.1086/692111.

Allcock, A.L., Strugnell, J.M., 2012. Southern Ocean diversity: new paradigms from molecular ecology. Trends Ecol. Evol. 27 (9), 520-528.

Barnes, D.K.A., Fleming, A., Sands, C.J., Quartino, M.L., Deregibus, D., 2018. Icebergs, sea ice, blue carbon and Antarctic climate feedbacks. Philos. Trans. R. Soc. A 376 (2122). https://doi.org/10.1098/rsta.2017.0176.

Beaumont, A.R., Wei, J.H.C., 1991. Morphological and genetic variation in the Antarctic limpet Nacella concinna (Strebel, 1908). J. Molluscan Studi. 57 (4), 443-450. https:// doi.org/10.1093/mollus/57.4.443.

Berry, R.J., Rudge, P.J., 1973. Natural selection in Antarctic limpets. Sci. Rep. Br. Antarct. Surv. 35, 73-81.

Bird, C.E., Holland, B.S., Bowen, B.W., Toonen, R.J., 2011. Diversification of sympatric broadcast-spawning limpets (Cellana spp.) within the Hawaiian archipelago. Mol. Ecol. 20 (10), 2128-2141. https://doi.org/10.1111/j.1365-294X.2011.05081.x.

Bolnick, D.I., Nosil, P., 2007. Natural selection in populations subject to a migration load. Evolution 61 (9), 2229-2243. https://doi.org/10.1111/j.1558-5646.2007.00179.x.

Bolnick, D.I., Barrett, R.D.H., Oke, K.B., Rennison, D.J., Stuart, Y.E., 2018. (Non) Parallel Evolution. Annu. Rev. Ecol. Evol. Syst. 49, 303-330.

Brêthes, J.-C., Ferreyra, G., de la Vega, S., 1994. Distribution, growth and reproduction of the limpet Nacella (Patinigera) concinna (Strebel 1908) in relation to potential food availability, in Esperanza Bay (Antarctic Peninsula). Pol. Biol. 14, 161-170.

Butlin, R.K., Saura, M., Charrier, G., Jackson, B., André, C., Caballero, A., Coyne, J.A., Galindo, J., Grahame, J.W., Hollander, J., Kemppainen, P., Martínez-Fernández, M., Panova, M., Quesada, H., Johannesson, K., Rolán-Alvarez, E., 2014. Parallel evolution of local adaptation and reproductive isolation in the face of gene flow. Evolution 68 (4), 935-949. https://doi.org/10.1111/evo.12329.

Caetano, D.S., Harmon, L.J., 2019. Estimating correlated rates of trait evolution with uncertainty. Syst. Biol. 68 (3), 412-429. https://doi.org/10.1093/sysbio/syy067.

Carreira, G.P., Shaw, P.W., Gonçalves, J.M., McKeown, N.J., 2017. Congruent molecular and morphological diversity of Macaronesian limpets: Insights into eco-evolutionary forces and tools for conservation. Front. Mari. Sci. 4, 1-15. https://doi.org/10.3389/ fmars.2017.00075.

Castillo, S., de Aranzamendi, M.C., Martínez, J.J., Sahade, R., 2019. Phenotypic selection by kelp gulls against pear-shaped shells of the Antarctic limpet Nacella concinna. Biol. J. Linn. Soc. 128 (3), 768-777. https://doi.org/10.1093/biolinnean/blz128.

Chan, Y.F., Marks, M.E., Jones, F.C., Villarreal, G., Shapiro, M.D., Brady, S.D., et al., 2010. Adaptive evolution of pelvic reduction in sticklebacks by recurrent deletion of a pitxl enhancer. Science 327 (5963), 302-305. https://doi.org/10.1126/ science.1182213.

Chwedorzewska, K.J., Korczak, M., Bednarek, P.T., Markowska-Potocka, M., 2010. Low genetic differentiation between two morphotypes of the gastropod Nacella concinna from Admiralty Bay, Antarctica. Pol. Res. 31 (2), 195-200. https://doi.org/10.4202/ ppres.2010.11.

Clark, M.S., Thorne, M.A.S., King, M., Hipperson, H., Hoffman, J.I., Peck, L.S., 2018. Life in the intertidal: Cellular responses, methylation and epigenetics. Funct. Ecol. 32 (8), 1982-1994. https://doi.org/10.1111/1365-2435.13077.

Collyer, M.L., Adams, D.C., 2013. Phenotypic trajectory analysis: Comparison of shape change patterns in evolution and ecology. Hystrix, It. J. Mamm. 24 (1), 75-83. https://doi.org/10.4404/hystrix-24.1-6298.

Collyer, M.L., Adams, D.C., 2018. RRPP: an r package for fitting linear models to highdimensional data using residual randomization. Methods Ecol. Evol. 9 (7), 1772-1779. https://doi.org/10.1111/2041-210X.13029.

Comiso, J.C., 2000. Variability and trends in Antarctic surface temperatures from In Situ and satellite infrared measurements. J. Clim. 13 (10), 1674-1696. https://doi.org/ 10.1175/1520-0442(2000)013<1674:VATIAS > 2.0.CO;2. 
Constable, A.J., Melbourne-Thomas, J., Corney, S.P., Arrigo, K.R., Barbraud, C., Barnes, D.K.A., et al., 2014. Climate change and Southern Ocean ecosystems I: How changes in physical habitats directly affect marine biota. Glob. Change Biol. 20 (10), 3004-3025. https://doi.org/10.1111/gcb.12623.

Cook, A.J., Holland, P.R., Meredith, M.P., Murray, T., Luckman, A., Vaughan, D.G., 2016 Ocean forcing of glacier retreat in the western Antarctic Peninsula. Science 353 (6296), 283-286. https://doi.org/10.1126/science.aae0017.

de Aranzamendi, M.C., Sahade, R., Tatián, M., Chiappero, M.B., 2008. Genetic differentiation between morphotypes in the Antarctic limpet Nacella concinna as revealed by inter-simple sequence repeat markers. Mar. Biol. 154 (5), 875-885. https://doi.org/10.1007/s00227-008-0980-5.

de Aranzamendi, M.C., Martínez, J.J., Sahade, R., 2010. Shape differentiation and characterization in the two morphotypes of the Antarctic limpet Nacella concinna using Elliptic Fourier analysis of shells. Pol. Biol. 33 (9), 1163-1170. https://doi. org/10.1007/s00300-010-0803-2.

de Aranzamendi, M.C., Bastida, R., Gardenal, C.N., 2011. Different evolutionary histories in two sympatric limpets of the genus Nacella (Patellogastropoda) in the Southwestern Atlantic coast. Mar. Biol. 158 (11), 2405-2418. https://doi.org/10.1007/ s00227-011-1742-3.

Deregibus, D., Quartino, M.L., Zacher, K., Campana, G.L., Barnes, D.K.A., 2017. Understanding the link between sea ice, ice scour and Antarctic benthic biodiversitythe need for cross-station and international collaboration. Polar Rec. 53 (2), 143-152. https://doi.org/10.1017/S0032247416000875.

Díaz, A., Gérard, K., González-Wevar, C., Maturana, C., Féral, J.P., David, B., et al., 2018. Genetic structure and demographic inference of the regular sea urchin Sterechinus neumayeri (Meissner, 1900) in the Southern Ocean: the role of the last glaciation. PLoS ONE 13 (6), 1-22. https://doi.org/10.1371/journal.pone.0197611.

Elena, S.F., Lenski, R.E., 2003. Evolution experiments with microorganisms: The dynamics and genetic bases of adaptation. Nat. Rev. Genet 4 (6), 457-469. https:// doi.org/10.1038/nrg1088.

Endler, J.A., 1986. Natural selection in the wild. Princeton University Press, Princeton; NJ.

Folmer, O., Hoeh, W.R., Black, M.B., Vrijenhoek, R.C., 1994. Conserved primers for PCR amplification of mitochondrial DNA from different invertebrate phyla. Mol. Mar. Biol. Biotechnol. 3 (5), 294-299.

Furuta, N., Ninomiya, S., Takahashi, S., Ohmori, H., Ukai, Y., 1995. Quantitative evaluation of soybean (Glycine $\max$ L. Merr.) leaflet shape by principal component scores based on elliptic Fourier descriptor. Breed Sci. 45, 315-320.

González-Wevar, C.A., David, B., Poulin, E., 2011a. Phylogeography and demographic inference in Nacella (Patinigera) concinna (Strebel, 1908) in the western Antarctic Peninsula. Deep-Sea Res. PT II 58 (1-2), 220-229. https://doi.org/10.1016/j. dsr2.2010.05.026.

González-Wevar, C.A., Nakano, T., Cañete, J.I., Poulin, E., 2011b. Concerted genetic, morphological and ecological diversification in Nacella limpets in the Magellanic Province. Mol. Ecol. 20 (9), 1936-1951. https://doi.org/10.1111/j.1365294X.2011.05065.x.

González-Wevar, C.A., Hüne, M., Cañete, J.I., Mansilla, A., Nakano, T., Poulin, E., 2012. Towards a model of postglacial biogeography in shallow marine species along the Patagonian Province: Lessons from the limpet Nacella magellanica (Gmelin, 1791). BMC Evol. Biol. 12 (1) https://doi.org/10.1186/1471-2148-12-139.

González-Wevar, C.A., Saucède, T., Morley, S.A., Chown, S.L., Poulin, E., 2013. Extinction and recolonization of maritime Antarctica in the limpet Nacella concinna (Strebel, 1908) during the last glacial cycle: Toward a model of Quaternary biogeography in shallow Antarctic invertebrates. Mol. Ecol. 22 (20), 5221-5236. https://doi.org/10.1111/mec.12465.

González-Wevar, C.A., Hüne, M., Rosenfeld, S., Saucède, T., Féral, J.P., Mansilla, A., Poulin, E., 2016. Patterns of genetic diversity and structure in Antarctic and subAntarctic Nacella (Patellogastropoda: Nacellidae) species. Biodiversity 17 (1-2), 46-55. https://doi.org/10.1080/14888386.2016.1181573.

González-Wevar, C.A., Hüne, M., Segovia, N.I., Nakano, T., Spencer, H.G., Chown, S.L., et al., 2017. Following the Antarctic Circumpolar Current: patterns and processes in the biogeography of the limpet Nacella (Mollusca: Patellogastropoda) across the Southern Ocean. J. Biogeogr. 44 (4), 861-874. https://doi.org/10.1111/jbi.12908.

Grange, L.J., Smith, C.R., 2013. Megafaunal communities in rapidly warming fjords along the West Antarctic Peninsula: Hotspots of abundance and beta diversity. PLoS ONE 8 (12). https://doi.org/10.1371/journal.pone.0077917.

Gutt, J., Bertler, N., Bracegirdle, T.J., Buschmann, A., Comiso, J., Hosie, G., et al., 2015. The Southern Ocean ecosystem under multiple climate change stresses - an integrated circumpolar assessment. Glob. Change Biol. 21 (4), 1434-1453. https:// doi.org/10.1111/gcb.12794.

Hamilton, A.M., Selwyn, J.D., Hamner, R.M., Johnson, H.K., Brown, T., Springer, S.K., Bird, C.E., 2020. Biogeography of shell morphology in over-exploited shellfish reveals adaptive trade-offs on human-inhabited islands and incipient selectively driven lineage bifurcation. J. Biogeogr. 47 (7), 1494-1509. https://doi.org/ $10.1111 /$ jbi.13845.

Hammer, Ø., Harper, D.A.T., Ryan, P.D., 2001. Past: Paleontological statistics software package for education and data analysis. Palaeontol. Electron. 4 (1), 1-9.

Hammerschlag, N., Barley, S.C., Irschick, D.J., Meeuwig, J.J., Nelson, E.R., Meekan, M. G., 2018. Predator declines and morphological changes in prey: Evidence from coral reefs depleted of sharks. Mar. Ecol. Prog. Ser. 586, 127-139. https://doi.org/ $10.3354 /$ meps 12426 .

Hawes, T.C., Worland, M.R., Bale, J.S., 2010. Freezing in the Antarctic limpet, Nacella concinna. Cryobiology 61, 128-132. https://doi.org/10.1016/j.

cryobiol.2010.06.006.
Held, C., Leese, F., 2007. The utility of fast evolving molecular markers for studying speciation in the Antarctic benthos. Pol. Biol. 30, 513-521. https://doi.org/ 10.1007/s00300-006-0210-x.

Hendry, A.P., Taylor, E.B., 2004. How much of the variation in adaptive divergence can be explained by gene flow? An evaluation using lake-stream stickleback pairs. Evolution 58 (10), 2319-2331. https://doi.org/10.1111/j.0014-3820.2004. tb01606.x.

Henley, S.F., Schofield, O.M., Hendry, K.R., Schloss, I.R., Steinberg, D.K., Moffat, C., et al., 2019. Variability and change in the west Antarctic Peninsula marine system: research priorities and opportunities. Prog. Oceanogr. 173, 208-237.

Hoffman, J.I., Peck, L.S., Hillyard, G., Zieritz, A., Clark, M.S., 2010. No evidence for genetic differentiation between Antarctic limpet Nacella concinna morphotypes. Mar. Biol. 157 (4), 765-778. https://doi.org/10.1007/s00227-009-1360-5.

Hoffman, J.I., Peck, L.S., Linse, K., Clarke, A., 2011. Strong Population Genetic Structure in a Broadcast-Spawning Antarctic Marine Invertebrate. J. Heredity 102 (1), 55-66. https://doi.org/10.1093/jhered/esq094.

Hoffman, J.I., Clarke, A., Clark, M.S., Fretwell, P., Peck, L.S., 2012. Unexpected fine-scale population structure in a broadcast-spawning antarctic marine mollusc. PLoS ONE 7 (3). https://doi.org/10.1371/journal.pone.0032415.

Iwata, H., Ukai, Y., 2002. SHAPE: a computer program package for quantitative evaluation of biological shapes based on Elliptic Fourier Descriptors. J. Heredity 93, 384-385.

Jacobs, A., Carruthers, M., Yurchenko, A., Gordeeva, N.V., Alekseyev, S.S., Hooker, O., et al., 2020. Parallelism in eco-morphology and gene expression despite variable evolutionary and genomic backgrounds in a Holarctic fish. PLoS Genetics 16 (4). https://doi.org/10.1371/journal.pgen.1008658.

Jones, F.C., Grabherr, M.G., Chan, Y.F., Russell, P., Mauceli, E., Johnson, J., et al., 2012. The genomic basis of adaptive evolution in threespine sticklebacks. Nature 484 (7392), 55-61. https://doi.org/10.1038/nature10944.

Kaeuffer, R., Peichel, C.L., Bolnick, D.I., Hendry, A.P., 2012. Parallel and non-parallel aspects of ecological, phenotypic, and genetic divergence across replicate population pairs of lake and stream stickleback. Evolution 66 (2), 402-418. https://doi.org/ 10.5061/dryad.k987h.

Katoh, K., Rozewicki, J., Yamada, K.D., 2019. MAFFT online service: multiple sequence alignment, interactive sequence choice and visualization. Brief. Bioinform. 20 (4), 1160-1166.

Kawecki, T.J., Ebert, D., 2004. Conceptual issues in local adaptation. Ecol. Lett. 7, 1225-1241.

Klaczko, J., Ingram, T., Losos, J., 2015. Genitals evolve faster than other traits in Anolis lizards. J. Zool. 295 (1), 44-48. https://doi.org/10.1111/jzo.12178.

Kumar, S., Stecher, G., Tamura, K., 2016. MEGA 7: molecular evolutionary genetics analysis version 7.0 for bigger datasets. Mol. Biol. Evol. 33, 1870-1874.

Langerhans, R.B., 2018. Predictability and parallelism of multitrait adaptation. J. Heredity 109 (1), 59-70. https://doi.org/10.1093/jhered/esx043.

Langerhans, R.B., DeWitt, T.J., 2004. Shared and unique features of evolutionary diversification. Am. Nat. 164 (3), 335-349.

Lau, S.C.Y., Wilson, N.G., Silva, C.N.S., Strugnell, J.M., 2020. Detecting glacial refugia in the Southern Ocean. Ecography 1-18. https://doi.org/10.1111/ecog.04951.

Leigh, J.W., Bryant, D., 2015. Popart: full-feature software for haplotype network construction. Methods Ecol. Evol. 6, 1110-1116.

Lomovasky, B.J., de Aranzamendi, M.C., Abele, D., 2020. Shorter but thicker: analysis of internal growth bands in shells of intertidal vs. subtidal Antarctic limpets, Nacella concinna, reflects their environmental adaptation. Pol. Biol. 43 (2), 131-141. https://doi.org/10.1007/s00300-019-02615-z.

Lowry, D.B., 2012. Ecotypes and the controversy over stages in the formation of new species. Biol. J. Linn. Soc. 106 (2), 241-257.

Lüdecke, D., 2020. Sjstats: Statistical Functions for Regression Models (Version 0.17.9).

Marcías, M.L., Deregibus, D., Saravia, L.A., Campana, G.L., Quartino, M.L., 2017. Life between tides: Spatial and temporal variations of an intertidal macroalgal community at Potter Peninsula, South Shetland Islands, Antarctica. Est. Coast. Shelf Sci. 187, 193-203. https://doi.org/10.1016/j.ecss.2016.12.023.

Markowska, M., Kidawa, A., 2007. Encounters between Antarctic limpets, Nacella concinna, and predatory sea stars, Lysasterias sp., in laboratory and field experiments. Mari. Biol. 151 (5), 1959-1966. https://doi.org/10.1007/s00227-007-0633-0.

Martinez, C.M., McGee, M.D., Borstein, S.R., Wainwright, P.C., 2018. Feeding ecology underlies the evolution of cichlid jaw mobility. Evolution 72 (8), 1645-1655. https://doi.org/10.1111/evo.13518.

Melo, D., Marroig, G., 2015. Directional selection can drive the evolution of modularity in complex traits. Proc. Natl. Acad. Sci. U.S.A 112 (2), 470-475. https://doi.org/ 10.1073/pnas.1322632112.

Morley, S.A., Clark, M.S., Peck, L.S., 2010. Depth gradients in shell morphology correlate with thermal limits for activity and ice disturbance in Antarctic limpets. J. Exp. Mar. Biol. Ecol. 390, 1-5. https://doi.org/10.1016/j.jembe.2010.04.040.

Mullen, L.M., Hoekstra, H.E., 2008. Natural selection along an environmental gradient: a classic cline in mouse pigmentation. Evolution 62, 1555-1570. https://doi.org/ 10.1111/j.1558-5646.2008.00425.x.

Nolan, C.P., 1991. Size, shape and shell morphology in the Antarctic limpet Nacella concinna at Signy Island, South Orkney Islands. J. Moll. Stud. 57 (2), 225-238. https://doi.org/10.1093/mollus/57.2.225.

Obermüller, B.E., Morley, S.A., Clark, M.S., Barnes, D.K.A., Peck, L.S., 2011. Antarctic intertidal limpet ecophysiology: A winter-summer comparison. J. Exp. Mar. Biol. Ecol. 403, 39-45. https://doi.org/10.1016/j.jembe.2011.04.003.

Oke, K.B., Bukhari, M., Kaeuffer, R., Rolshausen, G., Räsänen, K., Bolnick, D.I., Peichel, C.L., Hendry, A.P., 2016. Does plasticity enhance or dampen phenotypic parallelism? A test with three lake-stream stickleback pairs. J. Evol. Biol. 29 (1), 126-143. 
Oke, K.B., Rolshausen, G., LeBlond, C., Hendry, A.P., 2017. How parallel is parallel evolution? A comparative analysis in fishes. Am. Nat. 190 (1) https://doi.org/ 10.1086/691989.

Peck, L.S., Convey, P., Barnes, D.K.A., 2006. Environmental constraints on life histories in Antarctic ecosystems: Tempos, timings and predictability. Biol. Rev. Cambridge Phil. Soc. 81 (1), 75-109. https://doi.org/10.1017/S1464793105006871.

Peterson, B.K., Weber, J.N., Kay, E.H., Fisher, H.S., Hoekstra, H.E., 2012. Double digest RADseq: An inexpensive method for de novo SNP discovery and genotyping in mode and non-model species. PLoS One 7. https://doi.org/10.1371/journal. pone.0037135.

Powell, A.W.B., 1951. Antarctic and Subantarctic Mollusca: Pelecypoda and Gastropoda, Vol. 26. University Press.

R Development Core Team, 2019. R: A language and environment for statistical computing.

Raupach, M.J., Thatje, S., Dambach, J., Rehm, P., Misof, B., Leese, F., 2010. Genetic homogeneity and circum-Antarctic distribution of two benthic shrimp species of the Southern Ocean, Chorismus antarcticus and Nematocarcinus lanceopes. Mar. Biol. 157 (8), 1783-1797. https://doi.org/10.1007/s00227-010-1451-3.

Ravinet, M., Westram, A., Johannesson, K., Butlin, R., André, C., Panova, M., 2016. Shared and nonshared genomic divergence in parallel ecotypes of Littorina saxatilis at a local scale. Mol. Ecol. 25 (1), 287-305. https://doi.org/10.1111/mec.13332.

Roda, F., Ambrose, L., Walter, G.M., Liu, H.L., Schaul, A., Lowe, A., et al., 2013. Genomic evidence for the parallel evolution of coastal forms in the Senecio lautus complex. Mol. Ecol. 22 (11), 2941-2952. https://doi.org/10.1111/mec.12311.

Rogers, A.D., Frinault, B.A.V., Barnes, D.K.A., Bindoff, N.L., Downie, R., Ducklow, H.W., et al., 2020. Antarctic futures: An assessment of climate-driven changes in ecosystem structure, function, and service provisioning in the Southern Ocean. Ann. Rev. Mar. Sci. 12 (1), 7-34. https://doi.org/10.1146/annurev-marine-010419-011028.

Rohlf, F.J., Archie, J.W., 1984. A comparison of Fourier methods for the description of wing shape in mosquitoes (Diptera: Culicidae). Syst. Zool. 33, 302-317.

Rohlf, F.J., Corti, M., 2000. Use of two-block partial least-squares to study covariation in shape. Syst. Biol. 49 (4), 740-753.

Rozas, J., Ferrer-Mata, A., Sánchez-Del Barrio, J.C., Guirao-Rico, S., Librado, P., RamosOnsins, S.E., Sánchez-Gracia, A., 2017. DnaSP 6: DNA sequence polymorphism analysis of large data sets. Mol. Biol.Evol. 34, 3299-3302.

Santangelo, J.S., Johnson, M.T.J., Ness, R.W., 2018. Modern spandrels: the roles of genetic drift, gene flow and natural selection in the evolution of parallel clines. Proc. Royal Soc. B Biol. Sci. 285 (1878) https://doi.org/10.1098/rspb.2018.0230.

Schluter, D., Clifford, E.A., Nemethy, M., McKinnon, J.S., 2004. Parallel evolution and inheritance of quantitative traits. Am. Nat. 163 (6), 809-822.

Shabica, S.V., 1976. The natural history of the Antarctic limpet Patinigera polaris (Hombron and Jacquinot). PhD Thesis in Philosophy. Oregon State University.
Sherratt, E., Serb, J.M., Adams, D.C., 2017. Rates of morphological evolution, asymmetry and morphological integration of shell shape in scallops. BMC Evol. Biol. 17 (1), 248. https://doi.org/10.1186/s12862-017-1098-5.

Smith, C.R., DeMaster, D.J., Thomas, C., Sršen, P., Grange, L., Evrard, V., DeLeo, F., 2012. Pelagic- benthic coupling, food banks, and climate change on the West Antarctic Peninsula Shelf. Oceanography 25 (3), 188-201. https://doi.org/10.5670/ oceanog.2011.65.

Strebel, H., 1908. Dei Gastropoden. Wissenschaftliche Ergebn. Schwedisch SudpolarExpedition,1901-1903 6 (1), 1-112.

Stuart, Y.E., Veen, T., Weber, J.N., Hanson, D., Ravinet, M., Lohman, B.K., et al., 2017. Contrasting effects of environment and genetics generate a continuum of parallel evolution. Nat. Ecol. Evol. 1 (6), 1-7. https://doi.org/10.1038/s41559-017-0158.

Tsuboi, M., Gonzalez-Voyer, A., Kolm, N., 2015. Functional coupling constrains craniofacial diversification in Lake Tanganyika cichlids. Biol. Lett. 11 (5) https:// doi.org/10.1098/rsbl.2014.1053.

Vervust, B., Grbac, I., Van Damme, R., 2007. Differences in morphology, performance and behaviour between recently diverged populations of Podarcis sicula mirror differences in predation pressure. Oikos 116 (8), 1343-1352. https://doi.org/ 10.1111/j.2007.0030-1299.15989.x.

Walker, A.J.M., 1972. Introduction to the ecology of the Antarctic limpet Patinigera polaris (Hombron et Jacquinot) at Signy Island, South Orkney Islands. Brit. Antarc. Surv. Bull. 28, 49-69.

Waller, C.L., Worland, M.R., Convey, P., Barnes, D.K.A., 2006. Ecophysiological strategies of Antarctic intertidal invertebrates faced with freezing stress. Pol. Biol. 29, 1077-1083. https://doi.org/10.1007/s00300-006-0152-3.

Weihe, E., Abele, D., 2008. Differences in the physiological response of inter- and subtidal Antarctic limpets Nacella concinna to aerial exposure. Aquat. Biol. 4 (2), 155-166. https://doi.org/10.3354/ab00103.

Westram, A.M., Galindo, J., Alm Rosenblad, M., Grahame, J.W., Panova, M., Butlin, R.K., 2014. Do the same genes underlie parallel phenotypic divergence in different Littorina saxatilis populations? Mol. Ecol. 23 (18), 4603-4616. https://doi.org/ 10.1111/mec.12883.

Westram, A.M., Panova, M., Galindo, J., Butlin, R.K., 2016. Targeted resequencing reveals geographical patterns of differentiation for loci implicated in parallel evolution. Mol. Ecol. 25 (13), 3169-3186. https://doi.org/10.1111/mec.13640.

Westram, A.M., Faria, R., Johannesson, K., Butlin, R., 2021. Using replicate hybrid zones to understand the genomic basis of adaptive divergence. Mol. Ecol. https://doi.org/ $10.1111 /$ mec.15861.

Zink, R.M., Barrowclough, G.F., 2008. Mitochondrial DNA under siege in avian phylogeography. Mol. Ecol. 17 (9), 2107-2121. 